\title{
II SEMINÁRIO
}

\section{SOBRE ABORDAGEM MULTIDISCIPLINAR}

\section{NO TRATAMENTO DE FERIDAS CRÔNICAS}
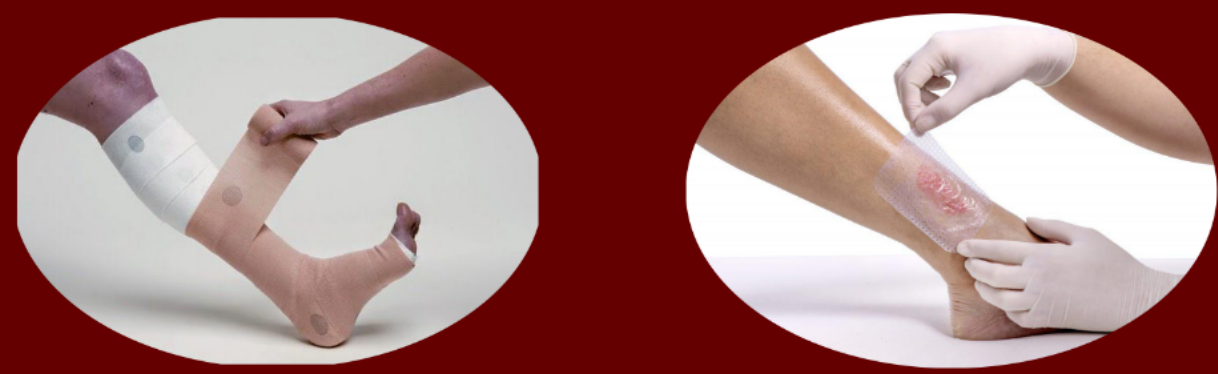

\section{ANAIS}

REALIZAÇÃO:

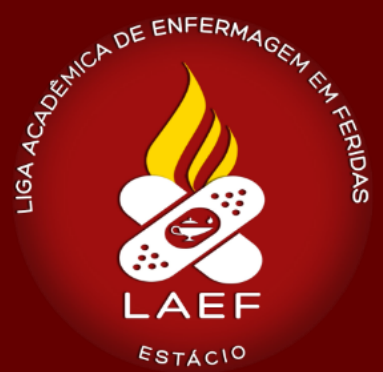

APOIO:
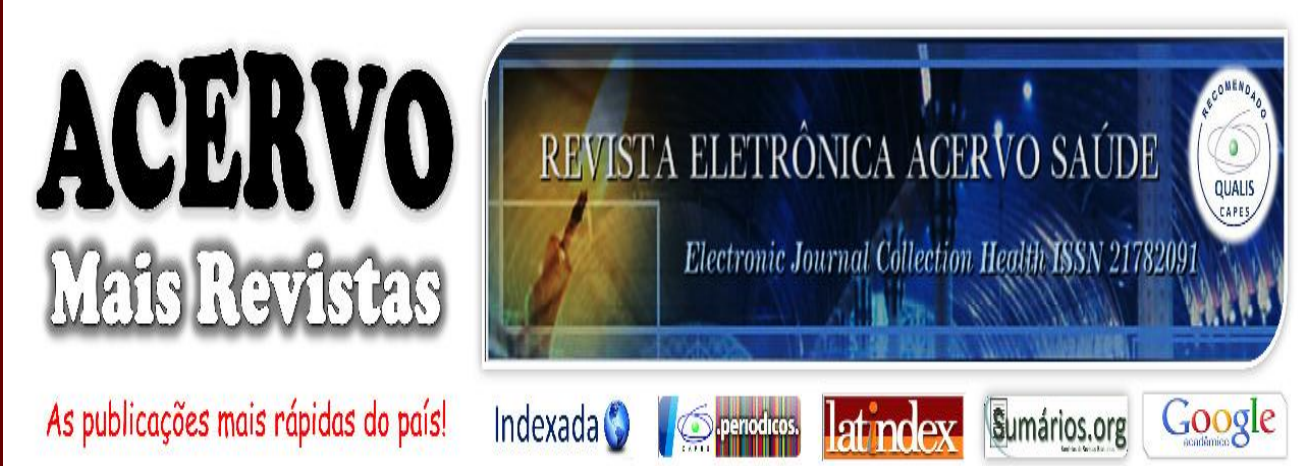


\section{Apresentação}

O II Seminário Sobre Abordagem Multidisciplinar no Tratamento de Feridas Crônicas realizado pela Liga Acadêmica de Enfermagem em Feridas (LAEF), ocorreu no dia 20 de setembro de 2019, no Centro Universitário Estácio de Sergipe. A coordenação geral do evento esteve sob responsabilidade da Orientadora fundadora

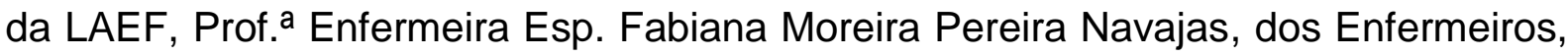
ex-ligantes e co-orientadores Douglas Vinicius dos Santos Feitosa e Noemia Santos de Oliveira Silva, além dos esforços de todos os demais ligantes e orientadoras adjuntas da LAEF.

O II Seminário Sobre Abordagem Multidisciplinar no Tratamento de Feridas Crônicas teve como objetivo reunir estudantes e profissionais das múltiplas áreas de estudo e trabalho com tratamento de feridas, a fim de discutir de modo científico e multiprofissional alguns temas que afligem as condições de vida e a saúde dos pacientes portadores de feridas crônicas e proporcionar difusão de conhecimento para um melhor desempenho profissional em cada situação.

O Seminário discutiu por meio de diversas palestras a avaliação de feridas, tratamento convencionais e coadjuvantes em lesões, a influência da alimentação no processo de cicatrização, o papel do fisioterapeuta frente ao portador de lesão neuropática, além de discussão por meio de mesa redonda tendo como questão norteadora a abordagem da equipe multidisciplinar na prevenção da lesão por pressão e apresentações de trabalhos científicos.

O evento contou com a presença de renomados profissionais de Aracaju SE, das áreas de Enfermagem (Esp. Gleyce Kelly de Brito Brasileiro Santos; Esp. Rafael Nascimento Déda Mendonça; Esp. Sindy Lamônie do Espirito Santo Barbosa e Ana Paula Aragão Santos), Nutrição (Esp.ìllana Tavares Costa e Marcela Larissa Costa), Fisioterapia (Jamilly Pinto Ferreira), Farmácia (Dayane Meire dos Santos), Psicologia (Beatriz Ávila Fontes Silva) e Fonoaudiologia (Ítala Queiroz). 
Parabenizamos todos os autores pelo empenho e dedicação a seus trabalhos científicos submetidos e apresentados em nosso evento e agradecemos à Revista Eletrônica Acervo Saúde pela publicação dos Anais do II Seminário com Abordagem Multidisciplinar no Tratamento de Feridas Crônicas - 2019. Esperamos que a centelha despertada neste evento sobre a importância do trabalho multiprofissional no tratamento de feridas permaneça acesa e permita-nos repetir a experiência exitosa nos próximos anos.

Enfa. Esp. Fabiana Navajas Moreira Pereira Presidente da Comissão Organizadora. 


\section{COMISSÃO ORGANIZADORA DO II SEMINÁRIO SOBRE ABORDAGEM MULTIDISCIPLINAR NO TRATAMENTO DE FERIDAS CRÔNICAS - LAEF}

D Enfㄹ. Esp. Docente do Centro Universitário Estácio de Sergipe, Fabiana Navajas Moreira Pereira: Presidente geral do evento e Orientadora Presidente da LAEF;

DEnfä. Docente do Centro Universitário Estácio de Sergipe, Maria Morgana Lima Silva: Orientadora Adjunto da LAEF;

D Enf ${ }^{\text {a }}$. Docente do Centro Universitário Estácio de Sergipe, Gilmara Carvalho Nascimento: Orientadora Adjunto da LAEF;

D Enfㄹ. . Docente do Centro Universitário Estácio de Sergipe, Taynara Fontes Almeida: Orientadora Adjunto da LAEF;

- Enfermeira, Noemia Santos de Oliveira Silva: Membro Fundador da LAEF, exligante e co-orientadora;

> Enfermeiro, Douglas Vinicius dos Santos Feitosa: Ex-ligante e co-orientador;

$>$ Acadêmica de enfermagem do Centro Universitário Estácio de Sergipe, Ana Beatriz Cardoso Campos;

> Acadêmica de enfermagem do Centro Universitário Estácio de Sergipe, Gécia Raquel dos Santos Barreto;

> Acadêmica de enfermagem do Centro Universitário Estácio de Sergipe, Raiane Marques dos Santos;

> Acadêmico de enfermagem do Centro Universitário Estácio de Sergipe, Átila Claed Dantas Oliveira;

- Acadêmica de enfermagem do Centro Universitário Estácio de Sergipe, Ana Carolina Sales dos Santos;

> Acadêmica de enfermagem do Centro Universitário Estácio de Sergipe, Viviana do Espiríto Santos; 
> Acadêmica de enfermagem do Centro Universitário Estácio de Sergipe, Maria Jucélia dos Anjos Santos;

> Acadêmica de enfermagem do Centro Universitário Estácio de Sergipe, Cleane Patricia dos Santos;

Acadêmica de enfermagem do Centro Universitário Estácio de Sergipe, Gilvantonia Bispo dos Santos;

> Acadêmica de enfermagem do Centro Universitário Estácio de Sergipe, Wadna Príscila Bomfim Lemos;

> Acadêmica de enfermagem do Centro Universitário Estácio de Sergipe, Hélia Caroline Gomes Oliveira;

Acadêmica de enfermagem do Centro Universitário Estácio de Sergipe, Tauane Pereira dos Santos. 
$>$ Presidente da comissão científica: Enfạ. Esp. Fabiana Navajas Moreira Pereira;

> Coordenadora geral da comissão científica: Enfermeiro, Douglas Vinicius dos Santos Feitosa;

> Diretora Financeira: Enfermeira, Noemia Santos de Oliveira Silva.

\section{BANCA AVALIADORA DOS TRABALHOS CIENTÍFICOS APRESENTADOS:}

> Enfermeira, Esp. na modalidade Residência Multiprofissional em Saúde do Adulto e Idoso, Mestranda em Enfermagem - UFS: Thaynara Fontes Almeida;

> Enfermeira, Esp. Mestranda em Ciência e Ambiente - Universidade Tiradentes: Ana Clara Cruz Santos de Santana;

> Enfermeiro, Pós-graduando em Docência em Enfermagem e Segurança do Paciente e Gestão de Risco Hospitalar: Douglas Vinicius dos Santos Feitosa;

Enfermeira, Pós-graduanda em Docência em Enfermagem e Enfermagem do Trabalho: Noemia Santos de Oliveira Silva. 


\section{PALESTRANTES E SEUS RESPECTIVOS TíTULOS DE PALESTRAS MINISTRADA NO II SEMINÁRIO SOBRE ABORDAGEM MULTIDISCIPLINAR NO TRATAMENTO DE FERIDAS CRÔNICAS - LAEF}

$>$ Enfermeira, Esp. na modalidade Residência Multiprofissional em saúde do Adulto e Idoso, Mestranda em Enfermagem - UFS, Gleyce Kelly de Brito Brasileiro Santos: Avaliação de Feridas;

> Enfermeiro, Esp. em Enfermagem Dermatológica, Rafael Nascimento Déda Mendonça: Tratamento Adjuvante X Convencionais em lesões;

> Nutricionista, íllana Tavares Costa: Influência da alimentação no processo de cicatrização;

> Enfermeira, Esp. na modalidade Residência Multiprofissional em Saúde do Adulto e Idoso, Mestranda em Enfermagem - UFS, Sindy Lamônie do Espirito santo Barbosa: Como identificar Úlcera venosa, arterial e mista;

> Fisioterapeuta, Residente do Programa Multiprofissional de em Saúde do Adulto e Idoso - UFS, Jamile Pinto Ferreira: O papel do fisioterapeuta frente ao paciente portador de lesão neuropática;

> Psicóloga, Residente do Programa Multiprofissional de em Saúde do Adulto e Idoso - UFS, Beatriz Ávila Fontes Silva: Aspectos emocionais nas relações sexuais do indivíduo portador de feridas crônicas;

$>$ Enfermeira, Residente do Programa Multiprofissional de em Saúde do Adulto e Idoso - UFS, Ana Paula Aragão Santos: Abordagem da equipe multidisciplinar na prevenção e tratamento de lesão por pressão;

> Nutricionista, Residente do Programa Multiprofissional de em Saúde do Adulto e Idoso - UFS, Marcela Larissa Costa: Abordagem da equipe multidisciplinar na prevenção e tratamento de lesão por pressão;

> Fonoaudióloga, Residente do Programa Multiprofissional de em Saúde do Adulto e Idoso - UFS, Ítala Queiroz: Abordagem da equipe multidisciplinar na prevenção e tratamento de lesão por pressão;

Farmacêutica, Residente do Programa Multiprofissional de em Saúde do Adulto e Idoso - UFS, Dayane Meire dos Santos: Abordagem da equipe multidisciplinar na prevenção e tratamento de lesão por pressão 
A IMPORTÂNCIA DO AUTOCUIDADO NA PREVENÇÃO DE LESÕES DO PÉ DIABÉTICO EM CLIENTES PORTADORES DE DOENÇAS CRÔNICAS..........11

ARRECADAÇÃO DE MEDICAMENTOS: REDUÇÃO DO RISCO DE INTOXICAÇÃ̃O POR AUTOMEDICAÇÃO E DO IMPACTO AMBIENTAL..........12 AS CONSEQUÊNCIAS DO USO PROLONGADO DOS ANTICONCEPCIONAIS ORAIS.

ASSISTÊNCIA DE ENFERMAGEM EM FERIDAS: PACIENTES PORTADORES DE TUMORES MALIGNOS.

ATUAÇÃO DO ENFERMEIRO NO TRATAMENTO DE LESÃO POR PRESSÃO NA UNIDADE DE TERAPIA INTENSIVA:UMA REVISÃO DE LITERATURA....15 BENEFÍCIOS DA UTILIZAÇÃO DA LASERTERAPIA: CONTRIBUIÇÃO DA ENFERMAGEM COM FOCO NA EVOLUÇÃO DO CUIDADO ÀS FERIDAS.....17 BENEFÍCIOS DA UTILIZAÇÃO DE SULFADIAZINA DE PRATA NO CUIDADO E TRATAMENTO DE FERIDAS POR QUEIMADURAS: REVISÃO DE LITERATURA.

ESTRATÉGIAS DO ENFERMEIRO FRENTE ÀS DIFICULDADES ENFRENTADAS PELAS PUÉRPERAS NA AMAMENTAÇÃO. .20

ESTUDO EPIDEMIOLÓGICO DA MORTALIDADE NA CIDADE DE ARACAJU NO ANO DE 2017 EM RAZÃO AO INFARTO AGUDO DO MIOCÁRDIO...........21

FITOTERAPIA: O USO DAS SUBSTÂNCIAS DE PLANTAS MEDICINAIS NO TRATAMENTO DE FERIDAS.

INDICAÇÕES E BENEFÍCIOS DA OXIGENOTERAPIA HIPERBÁRICA NO CUIDADO E TRATAMENTO DE FERIDAS CRÔNICAS.

INTERVENÇÕES DE ENFERMAGEM DIANTE PACIENTES ONCOLÓGICOS COM RADIODERMITE RELACIONADO A RADIOTERAPIA.

INTERVENÇÕES DO ENFERMEIRO NA PREVENÇÃO DE LESÃO POR PRESSÃO.

INTERVENÇÕES DO ENFERMEIRO NO PROCESSO DE DOAÇÃO DE ÓRGÃOS: UMMA REVISÃO DE LITERATURA.

LAPAROTOMIA: CUIDADOS DE ENFERMAGEM AOS PACIENTES COM DEISCÊNCIA DE FERIDAS OPERATÓRIAS.

LESÃO POR PRESSÃO: UTILIZAÇÃO DA ESCALA DE BRADEN COMO MÉTODO PREVENTIVO PELO ENFERMEIRO.

O ENFERMEIRO FRENTE À DEPRESSÃO PÓS-PARTO: REVISÃO INTEGRATIVA 
PERFIL EPIDEMIOLÓGICO DA MORTALIDADE MATERNA EM SERGIPE DEVIDO A PRÉ-ECLAMPSIA NOS ANOS DE 2012 À 2017.

PREVALÊNCIA DE FATORES DE RISCO PARA O CÂNCER DE MAMA EM SERGIPE.

PREVENÇÃO DA INFECÇÃO RESPIRATÓRIA ATRAVÉS DA HIGIENE ORAL EM PACIENTES ENTUBADOS NA UNIDADE DE TERAPIA

INTENSIVA

SELEÇÃO DE CURATIVOS: SEUS FATORES E SUA CAPACIDADE DE EFICÁCIA

SÍNDROME DE BURNOUT ENTRE OS PROFISSIONAIS DA ESTRATÉGIA DE SAÚDE DA FAMÍLIA.

SISPED: ABORDAGEM E PREVENÇÃO DE FERIDAS CRÔNICAS NO TRATAMENTO DO PÉ DIABÉTICO.

TERAPIA POR PRESSÃO NEGATIVA: EFICÁCIA NO TRATAMENTO DE FERIDAS CRÔNICAS

ÚLCERA VENOSA: ABORDAGEM DO ENFERMEIRO NA ASSISTÊNCIA AO PACIENTE NO ÂMBITO DA ATENÇÃO PRIMÁRIA À SAÚDE. 
II SEMINÁRIO SOBRE ABORDAGEM MULTIDISCIPLINAR NO TRATAMENTO DE FERIDAS CRÔNICAS

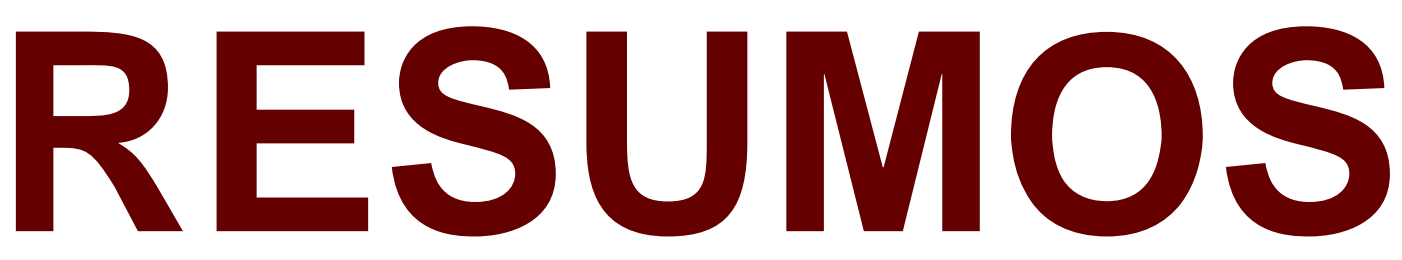




\section{A IMPORTÂNCIA DO AUTOCUIDADO NA PREVENÇÃO DE LESÕES DO PÉ DIABÉTICO EM CLIENTES PORTADORES DE DOENÇAS CRÔNICAS}

Taynara Silva dos Anjos ${ }^{1}$ (Acadêmica de Enfermagem, Centro Universitário Estácio de Sergipe). Fabiana Pereira Guimarães Brito ${ }^{2}$ (Docente do curso de Enfermagem, Centro Universitário Estácio de Sergipe)

1E-mail do autor correspondente: taynaraanjos9@gmail.com

INTRODUÇÃO: Levando em consideração a grande prevalência da diabetes tipo 2 no Brasil e no mundo em decorrência da mudança de hábitos de vida e alimentares, a doença gera um grande número de complicações como as amputações e lesões crônicas, gerando grande sofrimento que poderia ser evitado com as devidas precauções e adesão ao tratamento por parte dos pacientes ${ }^{1,2,3}$. OBJETIVO: Descrever a importância do autocuidado na prevenção de lesões do pé diabético em clientes portadores de doenças crônicas. METODOLOGIA: Trata-se de um estudo de revisão de literatura (bibliográfico) do tipo integrativo, descritivo e com abordagem qualitativa. Foram utilizadas as bases de dados LILACS, SciELO, MedLine e DeCS, de artigos científicos publicados entre 2009 e 2019. A seleção dos artigos foi feita de forma consistente, diante da importância de se prevenir lesões do pé diabético a partir do autocuidado de pessoas portadoras de doenças crônicas, em especial a diabetes mellitus. RESULTADOS: Uma das principais complicações da diabetes é a neuropatia que causa perda da sensibilidade dos membros e principalmente dos pés, porém ela pode ser evitada através de medidas preventivas. Além disso, a doença também gera complicações na cicatrização de feridas devido à instabilidade glicêmica adquirida. Desse modo, uma lesão aberta pode levar de meses a anos para serem cicatrizadas e em casos de prognósticos ruins, onde há infecção e necrose, levar a amputação ou perda efetiva de um membro. Ressalta-se a importância de realizar a prevenção elaborando estratégias no autocuidado, como por exemplo, o controle glicêmico, hidratação da pele, uso de calçado adequado e mudanças no estilo de vida. CONSIDERAÇÕES FINAIS: Os profissionais de saúde tem um papel fundamental no que diz respeito à orientação e ao acompanhamento dos cuidados necessários por parte dos pacientes. Desse modo, é imprescindível a aplicação de educação em saúde visando à conscientização de seus pacientes a fim de melhorar a adesão ao tratamento e melhorar a qualidade de vida além de um acompanhamento especializado que busque prevenir lesões precoces.

Palavras-chave: Autocuidado. Prevenção de Doenças. Diabetes Mellitus.

\section{REFERÊNCIAS:}

1. BEZERRA, F. S; et al. Os cuidados essenciais com os pés: percepções de diabéticos ulcerados. Revista Cadernos ESP, Ceará, v. 8, n. 2, p. 9-19, jul/dez. 2014.

2. COUTO, T. A. et al. Educação em saúde, prevenção e cuidado ao pé diabético: um relato de experiência. Revista Baiana de Saúde Pública, v. 38, n. 3, p. 760-768, jul/set. 2014.

3. FASSINA, G. et al. Avaliação do autocuidado em pacientes portadores do pé diabético. Revista da Faculdade de Ciências Médicas de Sorocaba, Sorocaba, v. 20, n. 4, p. 200-206, 2018. 


\title{
ARRECADAÇÃO DE MEDICAMENTOS: REDUÇÃO DO RISCO DE INTOXICAÇÃO POR AUTOMEDICAÇÃO E DO IMPACTO AMBIENTAL
}

\author{
Nayrane Kissiele Santos Oliveira' (Graduanda de Enfermagem do Centro Universitário Estácio de \\ Sergipe) \\ Sílvia Márcia dos Santos Sandes² (Mestra do Centro Universitário Estácio de Sergipe) \\ Makson Gleydson Brito de Oliveira ${ }^{3}$ (Doutor da Universidade Federal de Sergipe) \\ Alessa Caroline Pedroza de Vasconcelos ${ }^{4}$ (Doutora do Centro Universitário Estácio de Sergipe)
}

\section{E-mail do autor correspondente: nayranekibissele@outlook.com}

INTRODUÇÃO: A arrecadação de medicamentos possuiu o intuito de diminuir sobras, contribuir com o uso racional dos medicamentos e a redução do impacto sofrido pelo meio ambiente ${ }^{1,2}$. OBJETIVO: O presente estudo teve como objetivo analisar a quantidade de medicamentos arrecadados com o propósito de reduzir os riscos de intoxicação por automedicação e diminuir o impacto ambiental. METODOLOGIA: Estudo exploratório, retrospectivo com uma abordagem quantitativa e por conveniência, cujo principal propósito consistiu em arrecadar e caracterizar os medicamentos doados à Drogaria de Enfermagem (DROENF), projeto criado por acadêmicos de Enfermagem à favor da redução dos efeitos do uso irracional dos fármacos e conscientização sobre o descarte correto. Os dados foram coletados através de um formulário semiestruturado que avaliou as variáveis como classe terapêutica dos medicamentos doados, prazo de validade, forma farmacêutica, quantidade de medicamentos, sexo do doador. A coleta foi realizada na Faculdade Estácio de Sergipe, composta pelas doações dos medicamentos à DROENF, no período de agosto de 2017 a agosto de 2018. RESULTADOS: Ao total foram 213 doações, com predomínio do sexo feminino (55,86\%). A população variou entre 18 e 60 anos, sendo que a maior parte das doações ocorreu na faixa etária de 40 aos 49 anos (24,41\%). Foram arrecadados medicamentos válidos, totalizando 4196 fármacos (55,58\%), e 3354 vencidos (44,42\%), de diversas classes farmacológicas dentre elas, os Hormônios, que tiveram o maior número de doações, em contraponto com os Analgésicos, que apareceram em menor quantidade. $O$ maior quantitativo de forma farmacêutica foram os comprimidos. CONCLUSÃO: Esse estudo contribuiu para o uso racional dos medicamentos e para o descarte correto dos mesmos. Para evitar as intoxicações por automedicação e os impactos causados no meio ambiente, faz-se necessário uma gestão de resíduos de medicamentos, a conscientização da população e o controle da mídia, a promoção do uso racional dos mesmos e o tratamento de fármacos vencidos e danificados.

Palavras-chave: Automedicação. Intoxicação. Impacto ambiental. Medicamento. Contaminação. Meio ambiente.

\section{REFERÊNCIAS:}

1. DOMINGUES, P. H. F. et al. Prevalência da automedicação na população adulta do Brasil: revisão sistemática. Revista Saúde Pública, Amazonas, v.49, n.36, p.1-8, out, 2015.

2. AQUINO, D. S.; BARROS, J. A. C. De; SILVA, M. D. P. Da. A automedicação e os acadêmicos da área de saúde. Ciência \& Saúde Coletiva, Recife, v.15, n.5, p. 2533-38, maio, 2010. 
Allana Tarcisa Santos Morais ${ }^{1}$ (Acadêmica em Enfermagem, Universidade Tiradentes) Maria Darlla Santana Lima² (Acadêmica em Enfermagem, Universidade Tiradentes) Fernanda Dantas Barros ${ }^{3}$ (Orientadora, Enfermeira, Universidade Tiradentes)

1E-mail do autor correspondente: allanamorais10@gmail.com

INTRODUÇÃO: Os anticoncepcionais orais são muito utilizados pela população feminina trazendo inúmeros benefícios para a saúde como prevenção da gravidez e controle hormonal. Entretanto, como toda medicação essa também possui efeitos adversos, principalmente com seu uso prolongado ou contraindicado ${ }^{1,2}$. OBJETIVO: O objetivo da pesquisa é avaliar os riscos do uso prolongado das contracepções orais nas características e evolução clínica das mulheres, analisar a toxicidade dos contraceptivos e observar o conhecimento das mulheres que o utilizam. METODOLOGIA: Trata-se de uma revisão de literatura, com caráter qualitativo, realizada entre o período de 1 de abril à 25 de maio de 2019. Foi realizado levantamento bibliográfico, com recorte temporário de 2014 a 2019 nas bases de dados: LILACS e Scielo, utilizando como critério de inclusão artigos científicos disponíveis na íntegra, em idiomas português, inglês e espanhol, publicados nos últimos 5 anos e gratuitos. Como critérios de exclusão artigos duplicados, não disponíveis integralmente e relatos de caso, sendo selecionados onze artigos. RESULTADOS: Observou-se como resultado que mulheres com uso de concepção há mais de 10 anos tem propensão a lesões cervicais, além de apresentarem aproximadamente duas vezes maior nível de triglicerídeos em jejum, proteína C-Reativa e risco para trombose arterial. Em estudo da distribuição de zinco e remodelação óssea observou-se nas mulheres diminuição de zinco sendo $11 \%$ no total e $34 \%$ na excreção urinária, percebendo-se a modificação na distribuição de zinco com consequência na redução da remodelação óssea, aumentando o risco de osteoporose. Em análise, encontrou-se que mulheres com maior escolaridade e uso prolongado apresentavam maior conhecimento, sendo que as que não possuíam tal compreensão faziam uso das medicações incorretas e por não ter informação muitas tinham contraindicação para uso. Identificou-se a Síndrome de Budd-Chiari que ocorrem com uso dos anticoncepcionais e os sintomas desaparecem com a interrupção das medicações. CONSIDERAÇÕES FINAIS: A partir dos objetivos propostos observou como há um déficit na informação das contraindicações e utilização das medicações, sendo primordial repassar o conhecimento, modo de usar e os seus efeitos, pois grande parte das consequências ocorre por informações não compreendidas. Analisou-se também as toxicidades e riscos, principalmente físicos como aumento de níveis de triglicerídeos e proteína C-Reativa, além da propensão a lesões cervicais, trombose e osteoporose. Conclui-se que a contracepção pode trazer grandes benefícios, mas como toda medicação também pode causar alterações fisiológicas prejudiciais à saúde.

Palavras-Chave: Anticoncepcionais. Contraceptivos Orais. Saúde da Mulher.Fatores de Riscos.

\section{REFERÊNCIAS:}

1. ALMEIDA, Ana Paula Ferreira de; ASSIS, Mariana Mendes de. Efeitos colaterais e alterações fisiológicas relacionadas ao uso contínuo de anticoncepcionais hormonais orais. Revista Eletrônica Atualiza Saúde, Salvador, v. 5, n. 5, p. 85-93, jan/jun, 2017.

2. SANTOS, Alan Carlos Nery dos et al. C-Reactive Protein in Oral Contraceptive Users: Related Factors and Cardiovascular Risk. International Journal of Cardiovascular Sciences, v. 29, n. 4, p. 320-325, 2016. 


\section{ASSISTÊNCIA DE ENFERMAGEM EM FERIDAS: PACIENTES PORTADORES DE TUMORES MALIGNOS}

Esther Santos Lima' (Acadêmica de Enfermagem, Universidade Tiradentes) Yasmin Gonçalves Costa² (Acadêmica de Enfermagem, Universidade Tiradentes) Larissa Keylla Almeida de Jesus ${ }^{3}$ (Orientadora, Mestra em Saúde e Ambiente, Universidade Tiradentes)

1Email do autor correspondente: esther-lima092@outlook.com

INTRODUÇÃO: O tratamento de feridas cutâneas é um processo dinâmico dependente das fases de cicatrização - inflamatória, proliferativa e de maturação - que irá proporcionar a recuperação do tecido lesionado1. Porém, alguns diagnósticos, como o de câncer, na evolução do quadro fisiopatológico e clínico os pacientes podem desenvolver lesões características, denominadas feridas tumorais malignas, em que o processo de cura não é mais objetivado, pois a cicatrização é deficiente. Dessa forma, cabem aos profissionais da saúde, principalmente os enfermeiros, o domínio sobre conhecimento empírico e prático para discernir, entre fatores intrínsecos e extrínsecos, sobre os cuidados paliativos prestados, a fim de que a o convívio social e a qualidade de vida do paciente oncológico e dos seus familiares não seja reduzida devido às complicações relacionadas ao curativo². OBJETIVO: Identificar intervenções de enfermagem no tratamento de feridas neoplásicas. METODOLOGIA: Foi realizado um estudo teórico de abordagem qualitativa e quantitativa por meio de revisão de literatura na base de dados Scielo, utilizando referências no período de 2008 a 2018. RESULTADOS: Foram encontradas algumas lacunas sobre os conteúdos e técnicas para seleção do tratamento de feridas neoplásicas, além de concluir que alguns cuidados essenciais, como a limpeza e troca adequada não são executados. Na maioria dos casos, o principal fator encontrado decorrente de uma assistência inadequada é o odor fétido, determinante de restrições sociais para esses pacientes e seus familiares. Assim, as intervenções de enfermagem encontradas para o controle do odor foram: a técnica de desbridamento (autolítico, enzimático, mecânico e cirúrgico), avaliação do acometimento de sangramento em menos de sete dias, limpeza da ferida, utilização tópica de antibióticos e de soluções antissépticas, curativos oclusivos, coberturas com ação antimicrobiana, uso de bolsas coletoras, trocas no tempo correto e de acordo com a necessidade, identificação do caráter etiológico da ferida, descarte adequado do curativo sujo, habilidades de comunicação e educação em saúde. CONCLUSÃO: Mediante essa revisão literária é essencial que o enfermeiro realize cuidados baseados em evidências científicas, que proporcionam segurança ao paciente no manejo dos sinais e sintomas das feridas tumorais. Além de habilidades de comunicação para avaliação do estado emocional, social e espiritual do paciente.

Palavras-chave: Ferimentos e lesões. Cuidados paliativos. Enfermagem oncológica. Assistência ao paciente.

\section{REFERÊNCIAS:}

1. FREITAS, C. M. C. et al. Intervenções de enfermagem para pacientes oncológicos com odor fétido em ferida tumoral. Aquichan, Bogotá, v. 17, n. 3, p. 243-256, July, 2017.

2. AGRA, G. et al. Conhecimento e prática de enfermeiros no cuidado a pacientes com feridas tumorais malignas. Rev Cuid, Bucaramanga, v. 8, n. 3, p. 1849-1862, Dec. 2017. 


\title{
ATUAÇÃO DO ENFERMEIRO NO TRATAMENTO DE LESÃO POR PRESSÃO NA UNIDADE DE TERAPIA INTENSIVA - UMA REVISÃO DE LITERATURA
}

\author{
Emmely da Silva Leite ${ }^{1}$ (Especialista em oncologia- UNIASSELVE) \\ Gilmara Carvalho Nascimento² (Especialista em UTI e Urgência e Emergência- FATEC) \\ Graziele Jamily Martins Santos ${ }^{3}$ (Especialista em UTI e Urgência e Emergência- FATEC) \\ Viviane Freitas Andrade Goston ${ }^{4}$ (Mestre em Ciências da saúde - UFS)
}

1E-mail do autor correspondente: emmelyleite1234@gmail.com

INTRODUÇÃO: As lesões por pressão são lesões na pele e tecido subjacente que resultam da pressão contínua, fricção e cisalhamento. O tratamento das LPP's requer cuidados com uso de coberturas adequadas e limpeza para a prevenção e o surgimento de novas lesões. OBJETIVO: O objetivo deste estudo é conhecer as condutas dos enfermeiros intensivistas frente ao tratamento das lesões por pressão, tendo como base coberturas específicas e tratamentos inovadores em todos os estágios das lesões. METODOLOGIA: Trata-se de uma revisão integrativa que teve como fonte de dados BVS e Scielo, com acesso via internet, onde foram encontrados num total de 70 artigos. Os critérios de inclusão dos artigos foram trabalhos científicos publicados em português, texto na íntegra e disponíveis nas bases de dados selecionadas, compreendido no período entre 2008 a 2018, totalizando 20 artigos, que retratam sobre enfermeiro, lesão por pressão, prevenção, unidade de terapia intensiva. $E$ como critérios de exclusão: artigos que não atenderam a temática, escrito em outro idioma, anteriores ao período estabelecido, totalizando a exclusão de 50 artigos RESULTADOS: As principais coberturas utilizadas pelos enfermeiros no tratamento de LPP são: Alginato de cálcio, hidrocolóide, carvão ativado, sulfadiazina de prata, hidrogel, papaína, colagenase. As diretrizes para tratamento da LPP não aceitam o uso de antissépticos tópicos para a limpeza, pois são substâncias citotóxicas e dificultam a cicatrização. O tratamento das lesões vem sendo desenvolvido através de novas tecnologias, exigindo dos enfermeiros capacitação técnico científica para avaliar as feridas e indicar o produto adequado para cada uma delas. Há divergência entre os profissionais quanto às condutas realizadas no tratamento das LPP's, observando assim que os enfermeiros estabelecem cuidados importantes para plano de cuidado das lesões, contudo não o fazem de modo padronizado e baseado em evidências científicas atuais. É necessário treinamento e capacitação da equipe de enfermagem da UTI visando fornecer um tratamento de qualidade aos pacientes. Além do desenvolvimento de protocolos de intervenções de enfermagem para prevenção e tratamento da LPP voltados para pacientes críticos que devem ser revisados periodicamente, permitindo a padronização da assistência tendo ênfase na educação em saúde. CONCLUSÃO: Portanto o conhecimento profissional do enfermeiro eleva o nível da assistência, sabendo que a técnica de curativo em lesão por pressão em estágio avançado e privativo do enfermeiro. Além de descrever sobre os possíveis tratamentos para as LPP na UTI enfatizando a importância da educação continuada, do trabalho em equipe e da busca por conhecimento.

Palavras-chave: Lesão por pressão. Tratamento. Unidade de Terapia Intensiva.

\section{REFERÊNCIAS}

1. DANTAS, ALM; FERREIRA, PC; DINIZ, KD; MEDEIROS, ABA; LIRA, ALBC. 
Práticas do Enfermeiro Intensivista de Úlceras por Pressão. Revista Pesquisa Cuidado e Fundamental Online, v. 6, n. 2, p. 716-724, 2014.

2. NOGUEIRA MOREIRA et al. Condutas de enfermeiros no tratamento de feridas numa unidade de terapia intensiva. Revista da Rede de Enfermagem do Nordeste, $v$. 10, n. 2, abr-jun, p. 45-51, 2009. 


\title{
BENEFÍCIOS DA UTILIZAÇÃO DA LASERTERAPIA: CONTRIBUIÇÃO DA ENFERMAGEM COM FOCO NA EVOLUÇÃO DO CUIDADO ÀS FERIDAS
}

\author{
Sara Cristina de Andrade Farias ${ }^{1}$ (Acadêmica de Enfermagem, Universidade Tiradentes) \\ Breno Mota Santos Leite ${ }^{2}$ (Acadêmico de Enfermagem, Universidade Tiradentes) \\ Yasmim Barreto Santana ${ }^{3}$ (Acadêmica de Enfermagem, Universidade Tiradentes) \\ Beatriz Melo Almeida ${ }^{4}$ (Acadêmica de Enfermagem, Universidade Tiradentes) \\ Isabel Cristina Saboia Sturbelle ${ }^{5}$ (Orientadora, Mestra em Enfermagem, Universidade Tiradentes)
}

1E-mail do autor correspondente: sara.cristina@souunit.com.br

INTRODUÇÃO: Entende-se que o processo de feridas é um evento adverso que se caracteriza pela interrupção da conservação da pele ${ }^{1}$. Contudo, para que haja um reparo tecidual o organismo emprega um processo dinâmico que abrange eventos fisiológicos e bioquímicos, além da formação de tecido de granulação e regeneração de células especializadas, a fim de garantir de forma isolada o processo de regeneração². Diante dos avanços tecnológicos que contribui positivamente na assistência de enfermagem no tratamento de ferimentos e lesões, apresenta-se a laserterapia, a qual consiste em aplicação de laser de baixa potência capaz de promover os efeitos bioquímicos, bioelétricos e bioenergéticos, ativando a proliferação das células capazes de garantir o processo de cicatrização ${ }^{3}$. OBJETIVO: Analisar as vantagens oferecidas pela laserterapia na assistência oferecida para o tratamento de feridas e a sua aplicabilidade por enfermeiros. METODOLOGIA: Trata-se de uma revisão de literatura, onde foram identificados nove artigos publicados entre os anos de 2015 à 2018, tendo sido selecionados três que respondiam o objetivo do estudo. Utilizou-se as bases de dados LILACS, MEDLINE e BDENF e os descritores utilizados foram: Terapia a Laser AND Cuidados de Enfermagem e Terapia a Laser AND Ferimentos e Lesões, todos em português. RESULTADOS: Ao conceituar as informações dos artigos, percebe-se que os benefícios da laserterapia de baixa potência no tratamento de ferimentos e lesões é amplo, principalmente no que diz respeito aos benefícios voltados a analgesia, no processo anti-inflamatório e na cicatrização. Porém, existem poucas informações sobre sua aplicabilidade na assistência de enfermagem em um plano de cuidado. Todavia, a base de informação por parte da enfermagem neste contexto, obscurece a efetividade de um tratamento terapêutico eficaz, causando um impacto negativo na qualidade da assistência. A falta de informação sobre a laserterapia inflige negativamente no cuidado, diante disso, a enfermagem deve buscar o conhecimento de novas intervenções, sendo ela a laserterapia, uma das tecnologias que possui evidências fidedignas que comprova sua efetividade e através do conhecimento diminui a visão hospitalocêntrica de manusear lesões e feridas. CONCLUSÃO: Diante desse contexto, faz-se necessário que os profissionais de enfermagem instiguem seu conhecimento sobre a importância e eficácia de novas tecnologias no cuidado e tratamento de feridas, dentre elas a laserterapia, objetivando acelerar o processo de cicatrização, aumentar a perspectiva de vida dos pacientes e com isso beneficiar e proporcionar uma visão humanista na enfermagem.

Palavras-chave: Terapia a Laser. Cuidados de Enfermagem. Ferimentos e Lesões. Cicatrização. Desenvolvimento Tecnológicos.

\section{REFERÊNCIAS}

1. CUNHA, D. R. et al. Construção de um aplicativo multimídia em plataforma móvel para tratamento de feridas com laserterapia. Revista de Enfermagem, v. 12, n. 5, p. 1241-1249, 
2018.

2. LIBERATO, S. M. D. A enfermagem no manejo da dor em pessoas com úlcera venosa: revisão integrativa. J. res.: fundam. care. online, v. 8, n. 2, p. 4109-4120, 2016.

3. LIMA, N. E. P. et al. Laserterapia de baixa intensidade no tratamento de feridas e a atuação da enfermagem. Revista de Enfermagem da UFPI, v. 7, n. 1, p. 50- 56, 2018. 


\title{
BENEFíCIOS DA UTILIZAÇÃO DE SULFADIAZINA DE PRATA NO CUIDADO E TRATAMENTO DE FERIDAS POR QUEIMADURAS: REVISÃO DE LITERATURA
}

\author{
Breno Mota Santos Leite ${ }^{1}$ (Acadêmico de Enfermagem, Universidade Tiradentes) \\ Sara Cristina de Andrade Farias ${ }^{2}$ (Acadêmica de Enfermagem, Universidade Tiradentes) \\ Anny Karoline Menezes Santos ${ }^{3}$ (Acadêmica de Enfermagem, Universidade Tiradentes) \\ Beatriz Melo Almeida ${ }^{4}$ (Acadêmica de Enfermagem, Universidade Tiradentes) \\ Fernanda Kelly Fraga Oliveira ${ }^{5}$ (Orientadora, Mestre, Universidade Tiradentes)
}

1E-mail do autor correspondente: breno.mota@souunit.com.br

INTRODUÇÃO: Entende-se por queimaduras, qualquer ferimento ou traumatismo causados por agentes térmicos, químicos, elétricos ou radioativos, os quais provocam consequente destruição parcial ou total da pele e seus anexos, podendo atingir hipoderme, músculos, tendões e ossos. O tratamento, sobretudo, com sulfadiazina de prata, envolve cuidados locais e sistêmicos, variando de acordo com extensão/profundidade ${ }^{1,2}$. OBJETIVO: Descrever as vantagens da utilização de sulfadiazina de prata no cuidado e tratamento de feridas por queimaduras. METODOLOGIA: Trata-se de uma revisão de literatura. Ao total, foram identificados 17 artigos. Foram selecionados artigos publicados na íntegra entre os anos de 2014 e 2018, no idioma português, com indexação nas bases de dados LILACS, MEDLINE e SCIELO. A ferramenta utilizada de busca dos artigos foi a BVS, que engloba várias bases de dados, incluindo LILACS e MEDLINE. Os DeCS usados foram: Queimaduras; Unidades de Queimados; Cuidados de Enfermagem; Sulfadiazina de Prata. Em relação aos termos livres, as combinações utilizadas para a localização dos artigos foram: sulfadiazina de prata AND queimaduras (11), sulfadiazina de prata AND cuidados de enfermagem (3), sulfadiazina de prata AND unidades de queimados (3). RESULTADOS: Ao analisar os artigos, percebe-se que a sulfadiazina de prata (Ag-SD) possui amplo espectro antimicrobiano, é bastante recomendado no tratamento inicial de queimaduras de segundo e terceiro grau, é bactericida, porém devido à oxidação da prata, possui curta ação e, consequentemente, requer reaplicação ao menos diariamente do produto e necessidade de troca do curativo idealmente a cada 12 horas. Observa-se que, apesar de promover alterações significativas em relação ao tamanho da lesão, diminuição da quantidade de exsudato e surgimento dos tecidos de granulação e epitelial, o perfil de liberação da Ag-SD é dependente de vários fatores, entre eles, extensão e espessura da ferida. CONCLUSÃO: No que se refere à sulfadiazina de prata como modalidade terapêutica, verifica-se que o produto apresenta ação limitada se comparado ao desejado em um curativo ideal, ou seja, apesar de auxiliar na reepitelização e na cicatrização, o uso de curativos modernos, impregnados com prata, apresentam maiores vantagens, uma delas envolve a necessidade de troca do curativo espaçada, e não diariamente, minimizando dor e desconforto aos pacientes, além de apresentarem baixa toxicidade, ação rápida, e não provocar irritação ou sensibilização.

Palavras-chave: Queimaduras. Unidades de Queimados. Cuidados de Enfermagem. Sulfadiazina de Prata

\section{REFERÊNCIAS}

1. TAVARES, W. D. S; SILVA, R. S. D. Curativos utilizados no tratamento de queimaduras: uma revisão integrativa. Revista Brasileira de Queimaduras, v. 14, n. 4, p. 300-306, 2016.

2. METSAVAHT, U. L. D. Queimaduras e suas cicatrizes. Surg Cosmet Dermatol - SBD, v. 9, n. 4, p. 281-284, 2017. 


\title{
ESTRATÉGIAS DO ENFERMEIRO FRENTE ÀS DIFICULDADES ENFRENTADAS PELAS PUÉRPERAS NA AMAMENTAÇÃO
}

\author{
Michelly Karolaynny dos Santos(Acadêmica de Enfermagem, Centro Universitário Estácio de \\ Sergipe) \\ Jéssica de Jesus Santos² (Enfermeira, Centro Universitário Estácio de Sergipe) \\ Douglas Vinicius dos Santos Feitosa ${ }^{3}$ (Enfermeiro, Centro Universitário Estácio de Sergipe)
}

1E-mail do autor correspondente: michelly_karolaynny@hotmail.com

INTRODUÇÃO: O Aleitamento Materno Exclusivo é indispensável nos primeiros seis meses de vida da criança, pois garante um bom desenvolvimento, dispõe de propriedades nutricionais e imunológicas e previne doenças ${ }^{1}$. Porem existem vários fatores que interferem negativamente na amamentação ocasionando o desmame precoce ${ }^{2}$. OBJETIVO: verificar as principais dificuldades enfrentadas pelas puérperas durante a amamentação de acordo com a literatura. METODOLOGIA: Trata-se de uma revisão integrativa da literatura que descreveu as dificuldades enfrentadas pelas puérperas durante a lactação e o papel do enfermeiro como colaborador nesse processo de amamentação através das publicações indexadas na Biblioteca Virtual em Saúde, nas seguintes bases de dados: Base de Dados em Enfermagem (BDNENF), Literatura Latino-Americana e do Caribe em ciências as Saúde (LILACS) e na biblioteca eletrônica Sientific Eletronic Library Online (SciELO). RESULTADOS: A pesquisa possibilitou uma quantificação total de 21 artigos selecionados para o presente estudo demonstrando as dificuldades que as puérperas enfrentam durante o período de amamentação, ocasionando o desmame precoce, o papel do enfermeiro diante das orientações sobre o aleitamento materno exclusivo nos primeiros meses de vida do bebê e medidas que favorecem uma amamentação tranquila, sanando dúvidas e intercorrências. CONCLUSÃO: observou-se que apesar desse tema ser bastante comum na sociedade, ainda há taxas elevadas acerca do desmame precoce. Para isso constatou-se que o papel do enfermeiro na assistência a gestante e a puérpera é primordial para colaborar com a resolução dos fatores que influenciam essas mulheres a diminuir o tempo de aleitamento.

Palavras-chave: Aleitamento materno. Desmame. Amamentação. Puérpera na amamentação. Cuidados de enfermagem.

\section{REFERÊNCIAS}

1. CARNEIRO, L. M. M. C. et al. Prática do aleitamento materno por puérperas: fatores de risco para o desmame precoce. Revista Ciências da Saúde. Santa Maria, v. 15, n. 2, p. 239-248, 2014.

2. OLIVEIRA, A. C. et al. Aleitamento Materno Exclusivo: Causas da Interrupção na Percepção de Mães Adolescentes. Revista Enfermagem da Universidade Federal de

Pernambuco online, Recife, v.16, n. 4, p.1256-1263, abr, 2016. 


\title{
ESTUDO EPIDEMIOLÓGICO DA MORTALIDADE NA CIDADE DE ARACAJU NO ANO DE 2017 EM RAZÃO AO INFARTO AGUDO DO MIOCÁRDIO
}

\begin{abstract}
Kelly Dayane Evangelista de Oliveira ${ }^{1}$ (Enfermeira, Centro Universitário Estácio de Sergipe) Maria Luiza Silva Souza² (Enfermeira, Centro Universitário Estácio de Sergipe) Mayrane Acciole Gomes de Figueiredo ${ }^{3}$ (Enfermeira, Centro Universitário Estácio de Sergipe) Patricia Chaves Silva ${ }^{4}$ (Enfermeira, Centro Universitário Estácio de Sergipe)

Gabrielle Gomes da Fonseca ${ }^{5}$ (Enfermeira Mestre, Preceptora Centro Universitário Estácio de Sergipe)
\end{abstract}

1E-mail do autor correspondente: kelly27.dayane@gmail.com

INTRODUÇÃO: As doenças cardiovasculares (DCV) são alterações no funcionamento do sistema cardíaco e são consideradas um grande problema de saúde pública. São vários os fatores de risco relacionados ao desenvolvimento de DCV, dentre eles pode-se citar hiperlipidemia, tabagismo, obesidade, história familiar, idade, sexo e raça. O infarto agudo do miocárdio (IAM) é uma afecção isquêmica abrupta causada por um desequilíbrio entre oferta e demanda de nutrientes ao tecido. O principal sintoma é a dor torácica que ocorre subitamente e de forma contínua. OBJETIVO: Analisar o perfil epidemiológico de mortalidade em razão do infarto agudo do miocárdio na cidade de Aracaju no ano de 2017. METODOLOGIA: Trata-se de um estudo de descritivo com abordagem transversal e retrospectiva onde foi realizada uma análise epidemiológica sobre a mortalidade em razão do infarto agudo do miocárdio na cidade de Aracaju no ano de 2017 a partir de informações em saúde disponíveis na base de dados do DATASUS (Departamento de Informática do Sistema Único de Saúde). RESULTADOS: A análise dos dados foi realizada a partir da comparação do número de casos em relação a faixa etária compreendendo dos 20 aos 80 anos ou mais e comparação do número de casos entre o sexo feminino e sexo masculino. A partir da análise dos dados foi identificado que no ano de 2017 ocorreram um total de 166 (100\%) óbitos em razão do IAM. Em relação a faixa etária a que apresentou mais número de casos foi a de 60 a 69 anos com 50 (30\%) total dos casos. Em relação ao sexo, o sexo feminino apresentou maior número de casos com um total de um total de $94(57 \%)$ casos, sendo que a faixa etária com maior número de casos foi a de 80 anos ou mais com $35(37 \%)$ casos, nessa mesma faixa etária o sexo masculino apresentou 10 (13\%) casos. CONCLUSÃO: A partir dos dados obtidos, foi possível identificar que o maior número de óbitos ocorreu no sexo feminino, uma vez que as mulheres apresentam probabilidade maior de IAM quando comparada aos homens. E em relação a faixa etária a mais acometida por óbito foi a de 60 a 69 anos, uma vez que um dos fatores de risco para a ocorrência do IAM é a idade.

Palavras-chave: Doenças cardiovasculares. Infarto agudo do miocárdio. Perfil de saúde.

\section{REFERÊNCIAS:}

1. CARVALHO, D. C; PAREJA, D. C. T; MAIA, L. F. S. A importância das intervenções de enfermagem ao paciente com infarto agudo do miocárdio. Revista Cientifica de Enfermagem, São Paulo, v. 3, n. 8, p. 5-10, 2013.

2. COSTA, F. A. S. et al. Perfil demográfico de pacientes com infarto agudo do miocárdio no Brasil: Revisão integrativa. Revista sanare, v.17, n. 2, p. 66-73, jul/dez, 2018. 


\title{
FITOTERAPIA: O USO DAS SUBSTÂNCIAS DE PLANTAS MEDICINAIS NO TRATAMENTO DE FERIDAS
}

\begin{abstract}
Josefa Daiane dos Santos' (Graduanda em enfermagem, Universidade Tiradentes) Monielle de Jesus Silva² (Graduanda em enfermagem, Universidade Tiradentes) Deisyane Andrade de Oliveira ${ }^{3}$ (Graduanda em enfermagem, Universidade Tiradentes) Lidiane Revllan Ferreira Silva ${ }^{4}$ (Graduanda em enfermagem, Universidade Tiradentes) Fernanda Kelly Fraga Oliveira ${ }^{5}$ (Orientadora, Mestre, Universidade Tiradentes)
\end{abstract}

1Email do autor correspondente: josefadaianesantos@gmail.com

INTRODUÇÃO: O ferimento cutâneo se dar por meio de uma interrupção do tecido do corpo, que pode ser causada por meios traumáticos, seja ele de pequeno ou grande porte. Para a escolha do tratamento adequado avalia-se os fatores que podem ter causado esse ferimento, podendo ser por um processo interno ou externo'. A utilização de meios bioativos proporciona um custo muito abaixo em relação ao valor de medicamentos químicos ${ }^{2}$. A substância principal utilizada na fitoterapia são as plantas medicinais que são ricas em alcaloides, óleos essenciais, flavonoides e mucilagens (que possui grande poder na cicatrização) ${ }^{3}$. OBJETIVO: Identificar a eficácia da utilização de métodos fitoterápicos no tratamento de feridas. METODOLOGIA: Trata-se de uma revisão de literatura. No total, foram utilizados seis artigos. Os artigos selecionados foram publicados na íntegra entre os anos de 2016 e 2018, no idioma português, com indexação nas bases de dados SCIELO, BDENF e LILACS. A ferramenta utilizada para a busca de todos os artigos foi a BVS. Os DECs utilizados foram: fitoterapia, cicatrização e plantas medicinais. Em relação aos termos livres, as combinações utilizadas para a localização dos artigos foram: fitoterapia and tratamento de feridas e feridas and plantas medicinais. RESULTADOS: A partir dos resultados de artigos utilizados como referência desta revisão, deixam claro que a fitoterapia ganhou um espaço importante pela capacidade de reparação de tecidos com sua formulação capaz de promover eficácia na cicatrização das feridas. Algumas plantas medicinais foram destaques nos estudos quando os aspectos se tratavam da cicatrização de feridas, entre elas estavam o barbatimão e o cajueiro. Em outro estudo mostra os resultados na utilização do Phytoplenus plenusdermax, os mesmos foram satisfatórios, pois as cicatrizações completas das úlceras duraram cerca de 7,8 a 12,5 semanas. CONCLUSÃO: Diante das buscas na literatura pode-se concluir que, as utilizações das substâncias encontradas na flora brasileira são eficazes na cicatrização de feridas com comprovação obtida através de testes realizados em estudos pré-clínicos e clínicos. A cicatrização pode ser favorecida por meio de efeitos como: anti-inflamatório, antimicrobiano, atividade celular.

Palavras-chave: Cicatrização. Fitoterapia. Plantas medicinais.

\section{REFERÊNCIAS}

1. SILVA, P. S. G. et al. Atividade citotóxica, antimicrobiana e cicatrizante do extrato da Jatropha gossypiifolia L. Revista de Enfermagem, v.12, p. 465-74, 2018.

2. CHINI, L. T. et al. O uso de Aloe sp ( aloe vera) em feridas agudas e crônicas: revisão Integrativa. Rev. Universidade de La Sabana, v. 17, n.1, Jan/Mar., 2017.

3. BUZZI, M; FREITAS, F; WINTER, M. Cicatrização de úlceras por pressão com extrato plenusdermax de calêndula officinalis L. Revista Brasileira de Enfermagem, v. 69, n 2, p.18, 2016. 


\title{
INDICAÇÕES E BENEFÍCIOS DA OXIGENOTERAPIA HIPERBÁRICA NO CUIDADO E TRATAMENTO DE FERIDAS CRÔNICAS
}

\author{
Breno Mota Santos Leite' (Acadêmico de Enfermagem, Universidade Tiradentes) \\ Sara Cristina de Andrade Farias² (Acadêmica de Enfermagem, Universidade Tiradentes) \\ Josefa Daiane dos Santos ${ }^{3}$ (Acadêmica de Enfermagem, Universidade Tiradentes) \\ Steffany Souza de Santana ${ }^{4}$ (Acadêmica de Enfermagem, Universidade Tiradentes) \\ Isabel Cristina Saboia Sturbelle ${ }^{5}$ (Orientadora, Professora Assistente I, Enfermagem, Universidade \\ Tiradentes)
}

1E-mail do autor correspondente: breno.mota@souunit.com.br

INTRODUÇÃO: Entende-se por queimaduras, qualquer ferimento ou traumatismo causados por agentes térmicos, químicos, elétricos ou radioativos, os quais provocam consequente destruição parcial ou total da pele e seus anexos, podendo atingir hipoderme, músculos, tendões e ossos ${ }^{1}$. O tratamento, sobretudo, com sulfadiazina de prata, envolve cuidados locais e sistêmicos, variando de acordo com extensão/profundidade². OBJETIVO: Descrever as vantagens da utilização de sulfadiazina de prata no cuidado e tratamento de feridas por queimaduras. METODOLOGIA: Trata-se de uma revisão de literatura. Ao total, foram identificados 17 artigos. Foram selecionados artigos publicados na íntegra entre os anos de 2014 e 2018, no idioma português, com indexação nas bases de dados LILACS, MEDLINE e SCIELO. A ferramenta utilizada de busca dos artigos foi a BVS, que engloba várias bases de dados, incluindo LILACS e MEDLINE. Os DeCS usados foram: Queimaduras; Unidades de Queimados; Cuidados de Enfermagem; Sulfadiazina de Prata. Em relação aos termos livres, as combinações utilizadas para a localização dos artigos foram: sulfadiazina de prata AND queimaduras (11), sulfadiazina de prata AND cuidados de enfermagem (3), sulfadiazina de prata AND unidades de queimados (3). RESULTADOS: Ao analisar os artigos, percebe-se que a sulfadiazina de prata (Ag-SD) possui amplo espectro antimicrobiano, é bastante recomendado no tratamento inicial de queimaduras de segundo e terceiro grau, é bactericida, porém devido à oxidação da prata, possui curta ação e, consequentemente, requer reaplicação ao menos diariamente do produto e necessidade de troca do curativo idealmente a cada 12 horas. Observa-se que, apesar de promover alterações significativas em relação ao tamanho da lesão, diminuição da quantidade de exsudato e surgimento dos tecidos de granulação e epitelial, o perfil de liberação da Ag-SD é dependente de vários fatores, entre eles, extensão e espessura da ferida. CONCLUSÃO: No que se refere à sulfadiazina de prata como modalidade terapêutica, verifica-se que o produto apresenta ação limitada se comparado ao desejado em um curativo ideal, ou seja, apesar de auxiliar na reepitelização e na cicatrização, o uso de curativos modernos, impregnados com prata, apresentam maiores vantagens, uma delas envolve a necessidade de troca do curativo espaçada, e não diariamente, minimizando dor e desconforto aos pacientes, além de apresentarem baixa toxicidade, ação rápida, e não provocar irritação ou sensibilização.

Palavras-chave: Oxigenação Hiperbárica. Ferimentos e Lesões. Cicatrização. Cuidados de Enfermagem.

\section{REFERÊNCIAS:}

1. SILVA, A. C. D. Indicação de oxigenioterapia hiperbárica como auxiliar na cicatrização de úlceras de membro inferiores. Revista Médica de Minas Gerais, v. 28, p. 1-4, 2018. 


\title{
INTERVENÇÕES DE ENFERMAGEM DIANTE PACIENTES ONCOLÓGICOS COM RADIODERMITE RELACIONADO A RADIOTERAPIA
}

\begin{abstract}
Andriellen Rabelo Carvalho' (Acadêmica de Enfermagem. Centro Universitário Estácio de Sergipe) Maysa Araujo Silva ${ }^{2}$ (Acadêmica de Enfermagem. Centro Universitário Estácio de Sergipe) Paulo César Oliveira Barros Silva ${ }^{3}$ (Acadêmico de Enfermagem. Centro Universitário Estácio de Sergipe)

Ana Fátima Souza Melo de Andrade ${ }^{4}$ (Docente do curso de Enfermagem, Centro Universitário Estácio de Sergipe)
\end{abstract}

1E-mail do autor correspondente: andryebd@gmail.com

INTRODUÇÃO: O enfermeiro possui responsabilidade crucial ao prestar os cuidados contínuos aos pacientes oncológicos submetido a radioterapia, pois eles necessitam de uma atenção diferenciada, visto que o tratamento possui muitos efeitos adversos, tais como, a radiodermite que é considerada como uma reação cutânea ${ }^{1,2,3}$. OBJETIVO: Descrever a importância das intervenções de enfermagem voltado aos pacientes diagnosticados com radiodermite. METODOLOGIA: Trata-se de um estudo integrativo, descritivo e com abordagem qualitativa. Foram utilizadas as bases de dados LILACS, SciELO, MedLine e DeCS, de artigos científicos publicados entre 2015 a 2019. A seleção dos artigos foi feita de forma consistente, diante da importância da assistência de enfermagem onde baseia-se na prevenção de complicações por meio da higienização e hidratação da área irradiada. RESULTADOS: Evidenciou-se que o câncer é um dos problemas de saúde pública que está crescendo constantemente, devido à expectativa de vida que tem aumentado em consonância com o avanço da tecnologia, o que proporciona o crescimento de doenças crônicas. Logo, a equipe precisa desenvolver técnicas direcionadas para ação de prevenção, promoção, diagnóstico e tratamento. Desse modo, os profissionais possuem uma grande importância na vida desses pacientes, pois eles devem proporcionar uma assistência e um cuidado humanizado aos pacientes oncológicos no tratamento da radioterapia, sendo assim, eles necessitam de um atendimento qualificado sendo imprescindível que os profissionais de enfermagem tenham o amplo conhecimento para realizar a avaliação clínica, a execução de técnicas e uso assertivo das coberturas em conjuntos com ações preventivas das reações, para a prestação do cuidado eficaz e redução do tempo de interrupção das sessões de radioterapia ou que nem ocorram. CONSIDERAÇÕES FINAIS: O estudo possibilitou a geração de novas informações frente ao manejo de radiodermites. E ressaltou a importância das intervenções de enfermagem frente a essa complicação radioterápica com enfoque no conforto, alívio da dor e conscientização do cliente e da família, otimizando a adesão e qualidade do tratamento.

Palavras-chave: Radiodermite. Cuidado de enfermagem. Radioterapia.

\section{REFERÊNCIAS:}

1. BRASIL. Ministério da Saúde. Instituto Nacional de Câncer José Alencar Gomes da Silva. Incidência do câncer no Brasil: Rio de Janeiro, Ministério da Saúde, 2016.

2. GOLÇALVES, M. M. et al. Perfil dos atendimentos a pacientes oncológicos em uma unidade de pronto atendimento. Revista de Enfermagem do Centro-Oeste, v. 8, p. 25-95, 2018.

3. SCHNEIDER, F. DANSKI, M, T, R. VAYEGO, S, A. Usage of Calendula officinalis in the prevention and treatment of radiodermatitis: arandomized double-blind controlled clinical trial.

Rev. Esc. Enferm USP, São Paulo, v. 49, n. 2, p. 221-228, 2015. 


\section{INTERVENÇÕES DO ENFERMEIRO NA PREVENÇÃO DE LESÃO POR PRESSÃO}

Ana Paula Aragão Santos ${ }^{1}$ (Enfermeira, Centro Universitário Estácio de Sergipe) Douglas Vinicius dos Santos Feitosa ${ }^{2}$ (Enfermeiro, Centro Universitário Estácio de Sergipe) Noemia Santos de Oliveira Silva ${ }^{3}$ (Enfermeira, Centro Universitário Estácio de Sergipe) Fabiana Navajas Moreira Pereira ${ }^{4}$ (Enfermeira, Esp. Docente do Centro Universitário Estácio de Sergipe)

1E-mail do autor correspondente: enfanapaulaa@gmail.com

Introdução: A lesão por pressão tem se tornado um enorme problema de saúde pública, principalmente em pacientes crônicos que se encontram na terceira idade internados ou em tratamento a nível domiciliar ${ }^{1}$. Neste sentido, o aspecto preventivo, bem como o de promoção da saúde, procura guiar a prática assistencial para reduzir a incidência da lesão por pressão ${ }^{2,3}$. Objetivos: Objetivou-se revisar artigos que destacam o papel do enfermeiro frente avaliação e a prevenção da lesão por pressão. Metodologia: Trata-se de uma pesquisa exploratória de caráter bibliográfico, das bases de dados eletrônicas Scientific Electronic Library Online (SciELO), Base de Dados de Enfermagem (BDENF) e Latino-americana e do Caribe em Ciências da Saúde (LILACS). Os critérios de inclusão foram: artigos originais, completos e em português, publicados entre 2014 e 2018, em periódicos reconhecidos pelo QUALIS e que abordassem o objetivo proposto pelo estudo. Resultados: Foram mencionadas ações de prevenção como: avaliação do risco de LPP pela escala de Braden, o aporte nutricional balanceado, utilização de filme transparente de poliuretano e a placa hidrocoloide, reposicionamento planejado em angulação e com maior frequência, redução da exposição da pele à umidade e a utilização de artigos que modificam o pH da pele. Considerações finais: Assim, torna-se relevante a equipe multiprofissional, especialmente a equipe de enfermagem, a adoção de medidas voltadas para prevenção e condução deste agravo na instituição, sendo essencial associar teoria e prática baseadas em diretrizes com evidências que possam conduzir à prática clínica efetiva, com o intuito de se minimizar a incidência de LPP.

Palavras-Chave: Educação em enfermagem; Lesão Por Pressão; Prevenção; Promoção da Saúde.

\section{REFERÊNCIAS:}

1. DEBON, R. et al. A Visão de Enfermeiros Quanto a Aplicação da Escala de Braden no Paciente Idoso. Res fundam. care. Online, v. 10, n. 3, p. 817-823, jul-set, 2018.

2. INOUE, K. C; MATSUDA, L. M. Avaliação de Custo-Efetividade de Dois Tipos de Curativos Para Prevenção de Úlcera Por Pressão. Acta Paul Enferm, v. 28, n. 5, p. 415419, 2015.

3. LAURENTI, T. C. el al. Gestão Informatizada de Indicadores de Úlcera Por Pressão. J. Health Inform, v. 7, n. 3, p. 94-98, jul-set, 2015. 


\section{INTERVENÇÕES DO ENFERMEIRO NO PROCESSO DE DOAÇÃO DE ÓRGÃOS: UMA REVISÃO DE LITERATURA}

Taynara Silva dos Anjos ${ }^{1}$ (Acadêmica de Enfermagem. Centro Universitário Estácio de Sergipe). Fabiana Pereira Guimarães Brito² (Docente do curso de Enfermagem, Centro Universitário Estácio de Sergipe)

1E-mail do autor correspondente: taynaraanjos9@gmail.com

INTRODUÇÃO: O Brasil apresenta um dos maiores programas públicos de transplantes do mundo, e apesar do aumento no número de transplantes a cada ano, existe ainda uma discrepância entre a oferta e a demanda de órgãos em decorrência de questões econômicas, políticas, culturais e profissionais ${ }^{1}$. O transplante é em muitos casos a única possibilidade terapêutica, porém o processo de doação de órgãos e tecidos ainda é pouco compreendido pela população em geral ${ }^{2,3}$. OBJETIVO: Conhecer as intervenções do enfermeiro por meio das principais atividades desenvolvidas no processo de doação de órgãos e analisar a importância da assistência realizada pelo enfermeiro no processo de doação de órgãos. METODOLOGIA: Trata-se de um estudo exploratório de caráter bibliográfico e de abordagem quantitativa, apoiado nos artigos científicos publicados sobre as intervenções do enfermeiro no processo de doação de órgãos. Os dados foram tabulados pelo programa Excel versão 2010 para análise e interpretação dos resultados. RESULTADOS: Dos artigos pesquisados, $34,6 \%$ abordaram as intervenções do enfermeiro no processo de doação de órgãos, sendo elas: identificar e auxiliar na manutenção hemodinâmica do potencial doador; avaliar a viabilidade da doação; realizar a entrevista familiar para a doação de órgãos; prestar atendimento assistencial e integral a família na devolução do corpo pós-doação; criar, planejar, executar, coordenar, supervisionar e avaliar os procedimentos envolvidos no processo; realizar atividades com enfoque educativo; capacitar a equipe de enfermagem; participar no desenvolvimento do ensino e pesquisa nessa área. CONCLUSÃO: O enfermeiro desenvolve papel fundamental no processo de doação de órgãos e tecidos para transplante, porém as pesquisas realizadas demonstraram que apesar da importância do trabalho do enfermeiro ainda são necessárias inúmeras melhorias para que o processo de doação de órgãos possa atender à crescente demanda da população pelo serviço. Na prática, a melhoria do sistema depende da implantação de políticas públicas, sendo que tais ações passam também pela melhor capacitação do profissional de enfermagem.

Palavras-chave: Doação dirigida de tecidos. Morte encefálica. Cuidados de enfermagem.

\section{REFERÊNCIAS:}

1. PAZ, A. C. A. C; RIBEIRA, P. C. A; MASCARENHAS, M. D. M; SILVA, M. V. Caracterização dos doadores de órgãos e tecidos para transplante do estado do Piauí, de 2000 a 2009. Enfermagem em Foco, v. 2, n. 2, p. 124-127, 2011.

2. MATTIA, A. L; ROCHA, A. M; FILHO, J. P. A. F; BARBOSA, M. H; RODRIGUES, M. B; OLIVEIRA, M. G. Análise das dificuldades no processo de doação de órgãos: uma revisão integrativa da literatura. Revista Bioethikos, v. 4, n. 1, p. 66-74, 2010.

3. CICOLO, E. A; ROZA, B. A; SCHIRMER, J. Doação e transplante de órgãos: produção científica da enfermagem brasileira. Rev Bras Enferm, Brasília, v. 63, n. 2, p. 274-8, marabr, 2010. 


\section{LAPAROTOMIA: CUIDADOS DE ENFERMAGEM AOS PACIENTES COM DEISCÊNCIA DE FERIDAS OPERATÓRIAS}

Beatriz Melo Almeida ${ }^{1}$ (Acadêmica de Enfermagem, Universidade Tiradentes) Sara Cristina de Andrade Farias² (Acadêmica de Enfermagem, Universidade Tiradentes) Deisyane Andrade de Oliveira $^{3}$ (Acadêmica de Enfermagem, Universidade Tiradentes) Josefa Daiane dos Santos ${ }^{4}$ (Acadêmica de Enfermagem, Universidade Tiradentes) Isabel Cristina Saboia Sturbelle ${ }^{5}$ (Orientadora, Mestra em Enfermagem, Universidade Tiradentes)

1E-mail do autor correspondente: beatrizmelo9690@gmail.com

INTRODUÇÃO: A cirurgia de laparotomia exploratória caracteriza-se pela abertura da cavidade abdominal com finalidade terapêutica e diagnóstica, com intuito de avaliar a extensão de determinada patologia, além de outras possíveis doenças não identificada no processo diagnóstico. As complicações por sua vez são amplas, principalmente por ser um processo invasivo e propicio a infecção, devido a limitação de músculos e nervos ${ }^{1}$. Diante disso, a deiscência da ferida é uma das complicações, onde há um fracionamento das suturas logo nos primeiros dias do pós-operatório. Contudo, a equipe de enfermagem deve estar situada com as novas técnicas de coberturas e na atenção do pré e pós-operatório, para minimizar o insucesso cirúrgico². OBJETIVO: Analisar a aplicabilidade e os cuidados de enfermagem frente aos pacientes com deiscência cirúrgica descrito na literatura. METODOLOGIA: Trata-se de uma revisão de literatura, onde foram identificados cento e vinte e sete artigos publicados entre os anos de 2013 a 2014, tendo sido selecionados seis artigos que respondiam o objetivo do estudo. Utilizou-se as bases de dados SCIELO MEDLINE e LILACS e os descritores utilizados foram: Laparotomia AND Deiscência de feridas operatória, Cuidados de Enfermagem AND Deiscência de feridas operatória, todos em inglês. RESULTADOS: Compreende-se que a enfermagem dispõe de uma responsabilidade grande no que diz respeito à perfeita recuperação tecidual. A pele é o maior órgão do ser humano, diante disso, autores referem-se a necessidade da enfermagem em padronizar uma forma de curativo para minimizar danos no paciente e obter um processo de restauração eficaz. Entende-se que, o processo de deiscência da ferida na laparotomia, necessita de uma visão ampliada do enfermeiro, uma vez que essa pele será restaurada através de condições naturais e com a utilização de novas técnicas curativas. A fim de um tratamento eficaz, um dos artigos aborda que o curativo a vácuo é o mais indicado por estimular a formação do tecido de granulação e reduzir a colonização bacteriana devido ao alto índice de infecção. CONSIDERAÇÕES FINAIS: Baseado no grande risco de infecções que acontece na deiscência da laparotomia, os profissionais de enfermagem são o ponto chave para a aplicação de medidas preventivas. Desde o início, é primordial que o pré e pós-operatório sejam realizados adequadamente, porém, é importante que o enfermeiro adquira conhecimento das novas técnicas de coberturas para lidar com o acontecimento e minimizar danos físicos/emocionais aos pacientes.

Palavras-chave: Laparotomia. Deiscência de feridas operatória. Cuidados de Enfermagem. Cicatrização.

\section{REFERÊNCIAS:}

1. WALMING, S. et al. Retrospective review of risk factors for surgical wound dehiscence and incisional hernia. Revista BMC Surgery, v.17, n.19, p. 1-6,2017.

2. ZAIDI, A; EL-MASRY, S. Closed-incision negative-pressure therapy in high-risk general surgery patients following laparotomy: a retrospective study. Color Dis, v.19, n.3,p. 283-287, 2016. 


\section{LESÃO POR PRESSÃO: UTILIZAÇÃO DA ESCALA DE BRADEN COMO MÉTODO PREVENTIVO PELO ENFERMEIRO}

Josefa Daiane dos Santos ${ }^{1}$ (Graduanda em enfermagem, Universidade Tiradentes) Breno Mota Santos Leite ${ }^{2}$ (Graduando em enfermagem, Universidade Tiradentes) Deisyane Andrade de Oliveira ${ }^{3}$ (Graduanda em enfermagem, Universidade Tiradentes) Monielle de Jesus Silva ${ }^{4}$ (Graduanda em enfermagem, Universidade Tiradentes) Fernanda Kelly Fraga Oliveira ${ }^{5}$ (Orientadora, Mestre, Universidade Tiradentes)

1E-mail do autor correspondente: josefadaianesantos@gmail.com

INTRODUÇÃO: As lesões por pressão (LPP) trata-se de uma patologia que pode ser prevenida através de cuidados básicos realizados pela equipe de enfermagem, é definida como dano localizado em tecidos moles e na pele, o qual pode ser causada devido ao processo de fricção e cisalhamento em uma área rígida principalmente em indivíduos acamados ${ }^{1}$. A utilização da escala de Braden (EB) constitui um instrumento que o enfermeiro utiliza para avaliar o risco de desenvolver lesão por pressão². OBJETIVO: Conhecer a aplicabilidade da escala de Braden como método preventivo da lesão por pressão. METODOLOGIA: Trata-se de uma revisão de literatura narrativa realizada na base de dados biblioteca virtual em saúde (BVS). Durante consulta ao DECs, foram utilizados os descritores: Lesão por pressão; Enfermeiros e Avaliação. Foram incluídos somente os textos em português, dos anos de 2016 a 2019, tipos de literatura artigos citáveis e textos completos disponíveis, foram excluídos textos incompletos e indisponíveis além, das temáticas não relevantes ao alcance do objetivo e trabalhos duplicados. Foi retornado na base de dados BVS com o termo lesão por pressão and enfermeiros, diversos artigos que foram utilizados para construção de referencial teórico. RESULTADOS: A escala de Braden é um instrumento que visa avaliar o risco de desenvolvimento de lesão por pressão onde se observa a percepção sensorial, umidade, atividade, mobilidade, nutrição, friç̧ão e cisalhamento, que quando utilizada corretamente permite desenvolver mais ações de prevenção as lesões por pressão. A aplicabilidade da EB é indispensável em pacientes acamados, mediante avaliação e possibilidade de surgimento da LPP, para tanto, os profissionais deverão ser capacitados para compreender os critérios de classificação e assim realizar as intervenções pertinentes a diminuição dos fatores de risco para o paciente. A aplicação de um instrumento validado norteia as ações do enfermeiro e proporciona a uniformidade das práticas de todos os profissionais que aplicam o instrumento, além de outros protocolos que norteiam o serviço em relação à classificação de risco de desenvolver lesão por pressão. CONSIDERAÇõES FINAIS: Diante do exposto, o uso da Escala de Braden é importante para desenvolver atividades preventivas ao aparecimento das lesões por pressão, pois é um instrumento validado para nortear a prática do enfermeiro no atendimento e assistência prestada ao paciente.

Palavras-chave: Lesão por pressão. Cuidados de Enfermagem. Avaliação em Enfermagem.

\section{REFERÊNCIAS:}

1. DALLAROSA, F. S; BRAQUEHAIS, A. R. Conhecimento dos enfermeiros acerca da prevenção de lesões por pressão em unidade de terapia intensiva. Rev Enferm UFPI, v. 5, n. 4, p. 13-8, 2016.

2. CARVALHO, M. R. F; SALOMÉ G. M; FERREIRA L. M. Construção e validação de algoritmo para tratamento da lesão por pressão. Rev enferm UFPE on line, Recife, v.11, n. 10, p. 4171-83, 2017. 


\section{O ENFERMEIRO FRENTE À DEPRESSÃO PÓS-PARTO: REVISÃO INTEGRATIVA}

Michelly Karolaynny dos Santos ${ }^{1}$ (Acadêmica de Enfermagem, Centro Universitário Estácio de Sergipe)

Kamila Correia da Rocha² (Enfermeira, Centro Universitário Estácio de Sergipe)

Douglas Vinicius dos Santos Feitosa ${ }^{3}$ (Enfermeiro, Centro Universitário Estácio de Sergipe)

Adriana dos Santos Estevam ${ }^{4}$ (Enfermeira, Doutoranda em Biotecnologia- UFS)

1E-mail do autor correspondente: michelly_karolaynny@hotmail.com

INTRODUÇÃO: O período pós-parto é reconhecido como uma fase delicada na vida materna, por ser um período que a mulher fica mais vulnerável ao aparecimento de alguns transtornos, onde é necessária muita atenção ${ }^{1}$. A atual política de saúde da mulher, admitida pelo Ministério da Saúde, abrange o enfermeiro como profissional capacitado para realizar ações em todo o ciclo de vida feminino; como no período do pós-parto². OBJETIVO: O objetivo desse estudo foi reconhecer a importância do enfermeiro frente à pacientes com Depressão Pósparto (DPP). METODOLOGIA: Trata-se de uma revisão integrativa da literatura que descreveu conhecimento do profissional de enfermagem durante o período puerperal através de artigos encontrados na Biblioteca Virtual em Saúde (BVS), através das bases de dados eletrônicas: Base de Dados em Enfermagem (BDENF), Scientific Eletronic Library On-line (SciELO) e Literatura Latino-Americana e do Caribe em Ciências da Saúde (LILACS). RESULTADOS: A pesquisa possibilitou uma quantificação total de 21 artigos selecionados para o presente estudo demonstrando o papel do enfermeiro diante de pacientes com depressão pós-parto, demostrando conhecimento, foi relatado sobre sintomas psicológicos e a falta de apoio social para essas pacientes. CONCLUSÃO: Constatou-se que a maioria dos enfermeiros são aptos a prestar assistência de enfermagem específica e qualificada em relação à depressão pós-parto, assim como detectar o papel do enfermeiro durante todo o ciclo puerperal que consegue avaliar e identificar sinais e sintomas e chegar ao diagnóstico.

Palavras-chave: Depressão pós-parto. Enfermagem. Saúde Mental.

\section{REFERÊNCIAS:}

1. ABUCHAIM, E. S. V. et al. Depressão pós-parto e auto eficácia materna para amamentar: prevalência e associação. Revistas Científicas da América Latina, v. 29, n. 6, p. 664-670. 2012.

2. FÉLIX, T. A. et al. Atuação da enfermagem frente à depressão pós-parto nas consultas de puericultura. Revista electrónica trimestral de enfermagem, Cariré, v. 2, n. 29, p. 420-435, 2013. 


\title{
PERFIL EPIDEMIOLÓGICO DA MORTALIDADE MATERNA EM SERGIPE DEVIDO A PRÉ-ECLAMPSIA NOS ANOS DE 2012 À 2017
}

\author{
Maria Luiza Silva Souza ${ }^{1}$ (Enfermeira, Centro Universitário Estácio de Sergipe) \\ Kelly Dayane Evangelista de Oliveira² (Enfermeira, Centro Universitário Estácio de Sergipe) \\ Mayrane Acciole Gomes de Figueiredo ${ }^{3}$ (Enfermeira, Centro Universitário Estácio de Sergipe) \\ Patricia Chaves Silva ${ }^{4}$ (Enfermeira, Centro Universitário Estácio de Sergipe) \\ Ely Cecilia Gomes de Melo ${ }^{5}$ (Orientadora, Enfermeira docente, Centro Universitário Estácio de \\ Sergipe)
}

\section{1'E-mail do autor correspondente: maariaaluizaa@hotmail.com}

INTRODUÇÃO: A mortalidade materna é um importante problema de saúde pública no Brasil1. É definida pela Organização Mundial de Saúde como morte da mulher durante a gestação ou dentro de um período de 42 dias após o término da gravidez, independentemente da duração ou da localização da gravidez². A pré-eclâmpsia é uma desordem que pode ocorrer após a vigésima semana gestacional, durante o parto e até 48 horas pós-parto e é caracterizada pelo aumento tensional da pressão arterial e presença de proteinúria e/ou edema ${ }^{3}$. OBJETIVO: Analisar o perfil epidemiológico da mortalidade materna nos municípios do estado de Sergipe em virtude da pré-eclâmpsia nos anos de 2012 a 2017. METODOLOGIA: Trata-se de um estudo de descritivo com abordagem transversal e retrospectiva onde foi realizada uma análise epidemiológica sobre a mortalidade materna nos municípios do Estado de Sergipe a partir de informações em saúde disponíveis na base de dados do DATASUS (Departamento de Informática do Sistema Único de Saúde). RESULTADOS: De acordo com os dados disponibilizados pelo DATASUS, observou-se que no período de 2012 a 2017 ocorreram no Estado de Sergipe 21 óbitos de mulheres ocasionados por hipertensão gestacional com proteinuria na faixa etária de 15 a 49 anos, sendo que o maior número de óbitos registrados foi na faixa etária de 20 a 29 anos com 13 óbitos (61,90\%). O ano que apresentou mais óbitos registrados foi o de 2012 e 2013 com o total de 5 óbitos. O ano com menor registro foi o de 2015, pois não foi registrado nenhum óbito. As cidades com mais óbitos registrados foi a de Aracaju, com um total de 6 e em seguida vem a cidade de Nossa Senhora do Socorro com 3 óbitos. CONSIDERAÇÕES FINAIS: Com base nos resultados, evidenciou-se que a realização de um pré-natal de qualidade é fundamental para o rastreio de possíveis complicações que possam levar a mortalidade materna, uma vez que através do pré-natal é possível caracterizar o perfil das gestantes colhendo todas as informações sobre sua saúde, através dos antecedentes pessoais, obstétricos, ginecológicos, sociodemográficos e exame físico. Destaca-se ainda que é fundamental a elaboração de políticas públicas que estabeleçam estratégias adequadas para prevenção, diagnóstico precoce e tratamento das complicações na gestação que podem levar ao desfecho desfavorável da mortalidade materna.

Palavras-chave: Mortalidade materna. Perfil de saúde. Pré-eclâmpsia.

\section{REFERÊNCIAS:}

1. AMORIM, F. C. M. et al. Perfil de gestantes com pré-eclâmpsia. Revista de Enfermagem da UFPE online, Recife, v.11, n. 4, p.1574-1583, abr, 2017.

2. DIAS, J. M. G. et al. Mortalidade materna. Revista Médica de Minas Gerais, v.25, n.2, p.173-179, 2015.

3. FERREIRA, M. B. G et al. Assistência de enfermagem a mulheres com pré-eclâmpsia e/ou eclâmpsia: revisão integrativa. Revista da Escola de Enfermagem da USP, São Paulo, v. 50, n. 2, p. 324-344, 2016. 


\section{PREVALÊNCIA DE FATORES DE RISCO PARA O CÂNCER DE MAMA EM SERGIPE}

Ely Cecília Gomes Melo ${ }^{1}$ (Enfermeira, Centro Universitário Estácio) Noemia Santos de Oliveira Silva² (Enfermeira, Centro Universitário Estácio de Sergipe) Douglas Vinicius Santos Feitosa ${ }^{3}$ (Enfermeiro, Centro Universitário Estácio de Sergipe) Ana Paula Santos Aragão ${ }^{4}$ (Enfermeira, Centro Universitário Estácio) Adriana dos Santos Estevam ${ }^{5}$ (Enfermeira, Mestre e docente na Faculdade Uninassau) Thais Machado Santos Andrade ${ }^{6}$ (Co-orientadora, Mestre e docente no Centro Universitário Estácio de Sergipe).

Anne Aires Vieira Batista ${ }^{7}$ (Orientadora, Esp. docente no Centro Universitário Estácio de Sergipe)

1E-mail do autor correspondente: tay_machado123@hotmail.com

INTRODUÇÃO: O câncer de mama é considerado um problema de saúde pública de dimensões mundiais, sendo a principal causa de morte nas mulheres em todo o mundo, a segunda nos países desenvolvidos e a maior causa de morte nos países em desenvolvimento ${ }^{1}$. Conhecer sobre a situação dessa doença permite estabelecer prioridades e alocar recursos de forma direcionada para a modificação positiva desse cenário na população brasileira². OBJETIVO: traçar o perfil epidemiológico das mulheres jovens com câncer de mama. METÓDO: Trata-se de um estudo de coorte observacional retrospectivo, longitudinal de mulheres diagnosticadas com câncer de mama assistidas em um Hospital público referência no tratamento do câncer de mama. Os dados foram extraídos de fontes secundárias através da revisão sistemática do prontuário médico do paciente, do formulário de anotações de enfermagem utilizado no processo de enfermagem, da Autorização de Procedimentos de Alta Complexidade (APAC) e do Sistema de Informação Hospitalar (SIH). A amostra da pesquisa foi composta por pacientes com a faixa etária entre 20 a 40 anos, de qualquer raça; residentes no estado de Sergipe quando detectada a alteração na mama e que iniciaram quimioterapia no período de janeiro de 2015 a janeiro de 2016. RESULTADOS: O perfil da maioria dos pacientes com câncer de mama atendidas no HUSE é mulher na faixa etária de 37 anos, raça parda, procedência do interior, sem história prévia e familiar de câncer de mama, menarca aos 13 anos, gravidez antes dos 30 anos, não etilistas e com índice de massa corpórea em sobrepeso. CONCLUSÃO: Os resultados encontrados nessa pesquisa podem gerar mudanças nas políticas públicas tanto no âmbito local como nacional, melhor planejamento de estratégias voltadas à saúde da mulher, através da ampliação medidas educativas de prevenção do câncer de mama, como também da oferta e o acesso às ações de rastreamento, possibilitando o diagnóstico precoce da doença, melhores chances de cura e menores taxas de mortalidade

Palavras-chave: Perfil de saúde. Epidemiologia. Saúde da mulher. Neoplasias da mama.

\section{REFERÊNCIAS:}

1. BRASIL Instituto Nacional de Câncer José Alencar Gomes da Silva (INCA). Estimativa 2012: Incidência do Câncer no Mundo. Rio de Janeiro: Ministério da saúde, 2011.

2. BRASIL. Secretaria de Atenção à Saúde. Departamento de Atenção Básica. Controle dos cânceres do colo do útero e da mama. Brasília: Ministério da Saúde; 2013 


\title{
PREVENÇÃO DA INFECÇÃo RESPIRATÓRIA ATRAVÉS DA HIGIENE ORAL EM PACIENTES ENTUBADOS NA UNIDADE DE TERAPIA INTENSIVA
}

\author{
Alessandra Santana da Conceição' (Acadêmica de Enfermagem, Centro Universitário Estácio de \\ Sergipe); \\ Lisandra Mamede dos Santos ${ }^{2}$ (Enfermeira, Centro Universitário Estácio de Sergipe); \\ Adélia Alves Farias ${ }^{3}$ (Enfermeira, Centro Universitário Estácio de Sergipe); \\ Douglas Vinicius dos Santos Feitosa ${ }^{4}$ (Enfermeiro, Centro Universitário Estácio de Sergipe); \\ Fabiana Navajas Moreira Pereira ${ }^{5}$ (Enfermeira, Esp. em Obstetrícia, Centro Universitário Estácio de \\ Sergipe);
}

1E-mail do autor correspondente: alessandra-bittencurt1@hotmail.com

INTRODUÇÃO: A cavidade bucal deve ser vista por todos os profissionais de saúde como parte integrante do corpo e que não deve ser deixada de lado no cuidado do paciente hospitalizado. Ela deve ser tão bem assistida quanto qualquer parte do corpo ${ }^{1}$. Pacientes críticos hospitalizados, na maioria das vezes, não possuem higienização oral adequada, possivelmente em razão do desconhecimento de técnicas adequadas pelas equipes de terapia intensiva e da ausência do relacionamento interprofissional entre a odontologia e a enfermagem². OBJETIVO: A partir dessas constatações, esse estudo objetivou compreender a assistência de enfermagem frente aos pacientes entubados na UTI em relação à prevenção de infecções respiratórias relacionadas à higiene oral. METODOLOGIA: Trata-se de um estudo de revisão integrativa da literatura. A busca dos artigos se deu através da BVS, nas bases de dados BDENF, LILACS, BBO e MEDLINE. Foi encontrado um total de 14 artigos, sendo a maior parte distribuída para a base de dados LILACS e tem como prevalência as publicações do ano 2014. RESULTADOS: Observou-se que a higienização bucal é de vital importância para a prevenção de infecções respiratórias, devendo a enfermagem prestar uma atenção diferenciada a pacientes entubados, visto que esses não conseguem realizar a própria rotina de higiene bucal. A cavidade oral foi relatada como porta de entrada para microrganismos, devendo ser dispensada a esta uma atenção especial, principalmente nos casos em que haja presença de dispositivos externos. CONSIDERAÇÕES FINAIS: Concluise então que a higienização oral previne que microrganismos patogênicos tenham acesso ao sistema respiratório do paciente que, devido ao uso do tubo, encontra-se com maior risco para infecções.

Palavras-chave: Higiene bucal. Cuidados de enfermagem. Infecções respiratórias. Unidade de Terapia Intensiva.

\section{REFERÊNCIAS:}

1. SOUZA, A. F. et al. Avaliação da implementação do novo protocolo de higiene bucal em um centro de terapia intensiva para prevenção de pneumonia associada à ventilação mecânica. Revista Mineira de Enfermagem, v.17, n.1, p.177-184, 2013.

2. MOTA, E. C. et al. Incidência da pneumonia associada à ventilação mecânica em unidade de terapia intensiva. Revista Medicina, Ribeirão Preto, v. 50, n.1, p. 39-46, 2017. 


\title{
SELEÇÃO DE CURATIVOS: SEUS FATORES E SUA CAPACIDADE DE EFICÁCIA
}

\author{
Yasmin Gonçalves Costa' (Acadêmica de Enfermagem, Universidade Tiradentes) \\ Esther Santos Lima² (Acadêmica de Enfermagem, Universidade Tiradentes) \\ Larissa Keylla Almeida de Jesus ${ }^{3}$ (Orientadora, Mestra em saúde e ambiente, Universidade Tiradentes)
}

\section{'E-mail do autor correspondente: yasmingca2@gmail.com}

INTRODUÇÃO: O método de intervenção de feridas é dividido em clínico e cirúrgico, entre eles o clínico é o mais frequente, sendo o curativo o mais utilizado pelos profissionais. Definido como um instrumento terapêutico, em que se realiza limpeza e aplicação de materiais para a resolução do seu leito e ser capaz de ajudar na reepitelização em eventos diferentes ${ }^{1}$. A sua capacidade de êxito decorre do saber científico para a restauração tecidual, da escolha baseada em fatores internos e externos e também não menos relevante o quadro do paciente. A melhora do leito da ferida como resultante do curativo pode ser a intervenção final ou um artifício para reduzir os riscos, muitas vezes é fundamental o tratamento cirúrgico para o desfecho da ferida ${ }^{2}$. No mercado existem inúmeras coberturas desde a mais simples a mais complexa, sendo a escolha da utilização de acordo com as características da ferida e a que é mais adequada para a cicatrização, mediante: o tipo de exsudato, sua forma (aguda ou crônica), estágios de tratamento das feridas, número de colônias de bactérias e incentivo à granulação ${ }^{3}$. OBJETIVO: Analisar como ocorre a seleção dos curativos de acordo com suas características. METODOLOGIA: Trata-se de uma revisão integrativa da literatura científica de abordagem qualitativa e quantitativa, artigos realizados no Brasil de 2008 até 2019, consultado à base de dados Scielo. RESULTADOS: Os resultados demonstram as vantagens e desvantagens para escolha de certos curativos, além do seu mecanismo de ação e da sua composição, possibilitando os profissionais escolherem de acordo com as características da ferida e do quadro do paciente. Eles são: o curativo não-aderente, curativo não-aderente com silicone, filme transparente, espuma polimérica com ou sem prata, hidrocoloide, hidrogel, alginato de cálcio, carvão ativado e malha com prata. Sendo os dois mais utilizados: o carvão ativado com prata composto por fibras de carvão ativado com prata 0,15\%; absorvendo o exsudato e o odor, função bacteriostática (pela prata); indicado para feridas fétidas, exsudativas e infectadas e o alginato de cálcio composto por fibras de algas marinhas com cálcio; induzindo a hemostasia, absorvendo exsudatos, desbridamento autolítico, indicado para feridas abertas exsudativas, cavitárias e sangrantes. CONSIDERAÇÕES FINAIS: Por meio dessa revisão literária, nota-se os métodos de seleção para a escolha do curativo a ser utilizado e quais colaboram melhor para a reepitelização. Tendo em vista que sua eficácia na resolução da cicatrização está baseada nas características da lesão.

Palavras-chaves: Cicatrização. Terapêutica. Bandagem.

\section{REFERÊNCIAS:}

1. SMANIOTTO, P. H. S, GALLI, R; CARVALHO, V. F; FERREIRA, M. C. Tratamento clínico das feridas curativos. Rev Med, São Paulo, v. 89, n. 4, p. 137-41, jul-dez, 2010.

2. FRANCO, D; GONÇALVES, L. F. Feridas cutâneas: a escolha do curativo adequado. Rev Col Bras Cir, v. 35, n. 3, 2008 .

3. SOUZA, P; CASTRO, M; ISAAC, C. GALLI, R. Sistematização de curativos para o tratamento clínico das feridas. Rev Bras Cir Plást, v. 27, n. 4, p. 623-624, 2012. 


\title{
SÍNDROME DE BURNOUT ENTRE OS PROFISSIONAIS DA ESTRATÉGIA DE SAÚDE DA FAMÍLIA
}

\begin{abstract}
Valesca Souza Santana ${ }^{1}$ (Acadêmica de Enfermagem, Centro Universitário Estácio de Sergipe); Simone Cardoso de Jesus² (Acadêmica de Enfermagem, Centro Universitário Estácio de Sergipe); Douglas Vinicius dos Santos Feitosa ${ }^{3}$ (Enfermeiro, Centro Universitário Estácio de Sergipe);
\end{abstract}

1E-mail do autor correspondente: enfermakue@hotmail.com

INTRODUÇÃO: Embora o burnout não seja uma doença exclusiva de uma profissão específica, mas sim uma doença de diversas profissões, aquelas em que se lida com o sofrimento alheio aumentam a vulnerabilidade para o adoecimento, neste caso destaca-se o risco para equipe de enfermagem. No Brasil, estudos apontam a presença da síndrome $\mathrm{m}$ profissionais da saúde e constatam índices de prevalência significativos, inclusive em profissionais da Estratégia de Saúde da Família (ESF) ${ }^{1,2}$. OBJETIVO: O presente estudo buscou conhecer o nível de estresse ocupacional bem como a ocorrência da síndrome de burnout nos profissionais da ESF. METODOLOGIA: Trata-se de um estudo de revisão integrativa da literatura. Para a busca dos artigos, foram utilizados fonte de pesquisa a Biblioteca Virtual de Saúde (BVS) e Google Acadêmico. Foram consultados os artigos publicados em bases de dados virtuais: Literatura Latino-Americana e do Caribe em Ciências da Saúde (LILACS), na Scientific Electronic Library Online (SciELO) e na Base de Dados de Enfermagem (BDENF). Ao final 15 artigos que respondem ao tema em questão foram selecionados e incluídos nesta revisão. A pesquisa foi realizada no mês de agosto de 2018 . Como descritores para encontrar o material a ser utilizado usou-se: síndrome de burnout, equipe de enfermagem, saúde da família e esgotamento profissional. RESULTADOS: Após análise dos artigos selecionados, utilizou-se 13 artigos que correspondiam ao objetivo proposto do estudo. Dessas pesquisas selecionadas, 84\% (11 artigos) foram da SciElo, $8 \%$ (01 artigo) da BDENF e 8\% (01 artigo) da LILACS. Observou-se que o quadro das pessoas que são atingidas por essa doença é cada vez maior. Segundo a Previdência Social, com base em dados de 2016, mais de 75 mil trabalhadores foram afastados de suas funções no período em razão de quadros depressivos, como o burnout. CONCLUSÃO: Ações para prevenção e redução dos casos de burnout nos profissionais de enfermagem do âmbito ESF é um debate de suma importância, visto que, estudos comprovam o quadro alarmante dessa situação. Ressalta-se a importância de realizar trabalhos constantes acerca do tema principalmente em campo, para verificar a incidência e principalmente para auxiliar na necessidade de promoção à saúde desses profissionais.

Palavras-chave: síndrome de Burnout. Equipe de Enfermagem. Saúde da Família. Esgotamento profissional.

\section{REFERÊNCIAS:}

1. ALBUQUERQUE, F. J. B; MELO, C. F; ARAÚJO NETO, J. L. Avaliação da Síndrome de Burnout em Profissionais da Estratégia Saúde da Família da Capital Paraibana. Psicologia: Reflexão e Crítica, v. 25, n. 3, p. 542-49, 2012.

2. BARBIAN, R.; NORA, C.R.D.; SCHAEFE, R. Práticas do enfermeiro no contexto da atenção básica: scoping review. Rev. Latino-Am. Enfermagem, v. 24, p. 2721, 2016. 


\section{SISPED: ABORDAGEM E PREVENÇÃO DE FERIDAS CRÔNICAS NO TRATAMENTO DO PÉ DIABÉTICO}

Sara Cristina de Andrade Farias ${ }^{1}$ (Acadêmica de Enfermagem, Universidade Tiradentes)

Breno Mota Santos Leite ${ }^{2}$ (Acadêmico de Enfermagem, Universidade Tiradentes)

Beatriz Melo Almeida ${ }^{3}$ (Acadêmica de Enfermagem, Universidade Tiradentes)

Anny Karoline Menezes Santos ${ }^{4}$ (Acadêmica de Enfermagem, Universidade Tiradentes)

Isabel Cristina Saboia Sturbelle ${ }^{5}$ (Orientador, Mestra em Enfermagem, Universidade Tiradentes)

1E-mail do autor correspondente: sara.cristina@souunit.com.br

INTRODUÇÃO: O Diabetes Mellitus (DM) é uma patologia caracterizada como um distúrbio metabólico crônico, o qual infere o comprometimento da função do pâncreas na realização da síntese de glicose ${ }^{1}$. Uma das complicações que acometem os portadores da DM é o pé diabético, considerado uma causa constante de hospitalizações ${ }^{2}$. Esse agravamento compromete a qualidade de vida dos portadores devido ao aumento da incidência de ulcerações e amputações, os quais prejudicam a capacidade locomotora do indivíduo e diminuem a perspectiva de vida. Constata-se uma escassez de informação dos profissionais e orientação fragilizada, resumido ao básico em relação ao cuidado e tratamento ineficaz, induzindo, significativamente o risco de desenvolvimento de úlceras. Diante disso, a utilização do Sistema Salvando o Pé Diabético (SISPED) tem como objetivo detectar precocemente o risco de desenvolver complicações nas extremidades ${ }^{3}$. OBJETIVO: Verificar as terapêuticas descritas na literatura sobre os cuidados com o pé diabético e a utilização do SISPED como ferramenta para prevenção de agravos. METODOLOGIA: Trata-se de uma revisão de literatura, onde foram identificados trinta e três artigos publicados entre os anos de 2015 a 2018, tendo sido selecionados oito artigos que respondiam o objetivo do estudo. Utilizou-se as bases de dados LILACS, MEDLINE e BDENF e os descritores utilizados foram: Pé Diabético AND Prevenção e Controle, Pé Diabético AND Educação em Saúde, todos em português. RESULTADOS: Percebe-se o aumento progressivo de morbimortalidade por ulcerações decorrente do pé diabético. Além disso, é notório que muitos pacientes não aderem a automonitorização glicêmica, à pratica de exercícios físicos e cuidados com os pés, o que pode acarretar no ressecamento da pele, rachaduras e calosidades nos pés. Um dos artigos retrata que o uso da papaína a $5 \%$ em um período prolongado promove a cicatrização e reepitelização nos casos de lesão instalada. Contudo, no que se refere a educação em saúde, é importante que os profissionais estabeleçam vínculos e fortaleçam informações que possam contribuir no tratamento de úlceras, afim de diminuir o agravamento da doença e o número de amputações referente a essa patologia. Nesse sentido, não se observou a utilização do SISPED para detecção precoce das complicações decorrentes da DM. CONCLUSÃO: Frente ao alto índice e aumento da DM, faz-se necessário que os profissionais utilizem o SISPED como uma forma de prevenção para o surgimento de úlceras. Além da conscientização dos portadores sobre a importância do controle glicêmico, os benefícios da atividade física e sobre os cuidados adequados com os pés.

Palavras-chave: Pé Diabético. Ferimentos e Lesões. Prevenção e Controle. Educação em Saúde. 


\section{REFERÊNCIAS:}

1. DIAS, J. J; SANTOS, F. L. L. S. M; OLIVEIRA, F. K. F. Visita Domiciliar como ferramenta de Promoção da Saúde do Pé Diabético Amputado. Revista de Enfermagem, v. 11, n. 12, p. 5464-5470, 2017.

2. PEREIRA, L. F. et al. Ações do enfermeiro na prevenção do pé diabético: o olhar da pessoa com diabetes mellitus. Revista online de pesquisa, v.9, n.4, p. 1008-1014, 2017.

3. SENTEIO, J. S. et al. Prevalência de fatores de risco para o desenvolvimento de pé diabético. Revista online de pesquisa, v. 10, n.4, p. 919- 925, 2018. 


\section{TERAPIA POR PRESSÃO NEGATIVA: EFICÁCIA NO TRATAMENTO DE FERIDAS CRÔNICAS}

Deisyane Andrade de Oliveira' (Acadêmica de Enfermagem, Universidade Tiradentes)

Yasmim Barreto Santana ${ }^{2}$ (Acadêmica de Enfermagem, Universidade Tiradentes)

Anny Karoline Menezes Santos ${ }^{3}$ (Acadêmica de Enfermagem, Universidade Tiradentes)

Steffany Souza de Santana ${ }^{4}$ (Acadêmica de Enfermagem, Universidade Tiradentes)

Isabel Cristina Saboia Sturbelle ${ }^{5}$ (Orientadora, Mestra em Enfermagem, Universidade Tiradentes)

1Email do autor correspondente: deisyandrade_@hotmail.com

INTRODUÇÃO: A terapia por pressão negativa (TPN) é uma modalidade terapêutica, a qual é aplicada em feridas complexas, exsudativas, com cicatrização dificultosa e que necessitam de um maior período de tratamento ${ }^{1}$. Além disso, é utilizada para a preparação do leito da ferida, para enxertos e fechamento cirúrgico, propiciando a cicatrização por segunda intenção². Também contribui para o desenvolvimento cicatricial por estimular a formação de tecido de granulação, diminuição da colonização de bactérias, reduzindo assim os custos com outros tipos de curativos. Diante disso, é importante destacar a assistência de Enfermagem na manipulação da TPN, no processo de tratamento de feridas, para garantir uma melhor qualidade de vida para os pacientes ${ }^{3}$. OBJETIVO: Analisar a aplicabilidade da Terapia por Pressão Negativa descrita na literatura com ênfase na assistência de enfermagem no processo de cicatrização. METODOLOGIA: Trata-se de uma revisão de literatura, onde foram selecionados oito artigos que respondiam o objetivo desse estudo, publicados entre os anos de 2016 a 2018, no idioma português. Utilizou-se as bases de dados BVS, BDENF, LILACS e MEDLINE e os descritores utilizados foram: Terapia com pressão negativa AND ferimentos e lesões, Terapia com pressão negativa AND cuidados de enfermagem e Terapia por pressão negativa AND cicatrização. RESULTADOS: Diante dos artigos expostos, percebe-se a eficácia da TPN no processo de cicatrização de feridas complexas. Ao evidenciar o investimento da TPN, por mais que possua um custo elevado, quando comparado aos tratamentos convencionais, torna-se significativamente mais eficaz e de baixo custo, dessa forma, demonstra melhor custo benefício. A utilização dessa terapêutica favorece na assistência de Enfermagem e proporciona uma melhor recuperação do paciente. Contudo, faz-se necessário o aumento dessa prática, pelo fato de apresentar condições ideais para uma rápida cicatrização, além de proporcionar uma redução do tempo de internação e viabilizar uma melhor perspectiva de vida para o paciente, no que se refere à redução do edema, alívio da dor e estimulação da formação do tecido de granulação. CONSIDERAÇÕES FINAIS: A partir dos resultados, é possível concluir que a TPN é uma das formas de tratamento que favorece significativamente o paciente, no que diz respeito ao tempo de tratamento, a eficácia, a segurança e aplicabilidade na prática clínica, propiciando resultados positivos em relação a qualidade da assistência de enfermagem.

Palavras-chave: Ferimentos e lesões. Cicatrização. Tratamento de ferimentos com pressão negativa. Cuidados de enfermagem.

\section{REFERÊNCIAS:}

1. JONES, D. A. et al. Aplicação da terapia por pressão negativa no tratamento de feridas infectadas. Estudo de casos. Rev Bras Ortop, v. 51, n.6, p. 646-651, 2016.

2. LIMA, R. V. K. S. et al. Terapia por pressão negativa no tratamento de feridas complexas.

Rev. Col. Bras. Cir, v. 44, n.1, p. 81-93, 2017. 


\section{SEMINÁRIO SOBRE ABORDAGEM MULTIDISCIPLINAR NO TRATAMENTO DE FERIDAS CRÔNICAS}

3. RIBEIRO, Michele. et al. Eficácia do tratamento com pressão negativa na cicatrização de lesão por pressão. ESTIMA, v.15 n. 4, p. 240-244, 2017. 


\title{
ÚLCERA VENOSA: ABORDAGEM DO ENFERMEIRO NA ASSISTÊNCIA AO PACIENTE NO ÂMBITO DA ATENÇÃO PRIMÁRIA À SAÚDE
}

\author{
Deisyane Andrade de Oliveira' ${ }^{1}$ (Acadêmica de Enfermagem, Universidade Tiradentes) Yasmim \\ Barreto Santana² (Acadêmica de Enfermagem, Universidade Tiradentes) \\ Josefa Daiane dos Santos ${ }^{3}$ (Acadêmica de Enfermagem, Universidade Tiradentes) \\ Monielle de Jesus Silva ${ }^{4}$ (Acadêmica de Enfermagem, Universidade Tiradentes) \\ Fernanda Kelly Fraga Oliveira ${ }^{5}$ (Orientadora, Mestre, Universidade Tiradentes)
}

1E-mail do autor correspondente: deisyandrade_@hotmail.com

INTRODUÇÃO: A úlcera venosa é um tipo de lesão crônica que surge no terço inferior da perna e está relacionada à insuficiência venosa, sendo uma das causas principais de úlceras de membros inferiores. É apontada como um problema de saúde pública, em especial, por conta do aumento de sua incidência, criando um considerável motivo de desconforto e incapacidade, intervindo em muitos aspectos da vida dos pacientes, sobretudo na qualidade de vida ${ }^{1}$. Sendo assim, nota-se a significância do enfermeiro na assistência aos portadores de úlceras venosas, sobretudo o profissional que atua na Atenção Primária à Saúde (APS) prestando assistência contínua e integral2. OBJETIVO: Conhecer os principais cuidados do enfermeiro na assistência ao paciente com úlcera venosa. METODOLOGIA: Trata-se de uma revisão de literatura, onde foram selecionados oito artigos que respondiam o objetivo desse estudo publicados entre 2016 a 2018, no idioma português. Utilizou-se as bases de dados BVS, BDENF e LILACS e os descritores utilizados foram: Úlceras venosas AND Atenção Primária à Saúde, Cuidados de Enfermagem AND Úlceras venosas, e Cicatrização AND Úlceras venosas. RESULTADOS: Diante dos artigos expostos, percebe-se que a abordagem do profissional de enfermagem no cuidado ao paciente portador de úlcera venosa não deve ser apenas voltada para o tratamento da lesão, mas sim, uma assistência holística para propiciar uma melhoria na qualidade de vida. Ao evidenciar que a visita domiciliar cria um vínculo entre paciente e enfermeiro, isto é, fundamental para obter melhores resultados na assistência prestada, assim melhorando a capacidade funcional por meio de orientações em saúde. Foi apontado a utilidade de implementação de protocolo para os portadores de úlceras venosa atendidos na APS, para auxiliar na sistematização da assistência e no planejamento das intervenções, assim como, no seguimento dos cuidados e para qualificar as ações dos enfermeiros. CONCLUSÃO: Diante do exposto, conclui-se que a abordagem dos enfermeiros no cuidado aos pacientes é imprescindível para garantir uma recuperação e evitar que ocorra uma continuidade da lesão no paciente, assim como na prevenção de novos episódios. $O$ enfermeiro está inserido no tratamento e na prevenção das complicações decorrentes de úlceras venosas.

Palavras-chave: Úlcera Venosa. Cuidados de Enfermagem. Cicatrização. Atenção Primária à Saúde.

\section{REFERÊNCIAS:}

1. ARAÚJO, R. O. et al. Impacto de úlceras venosas na qualidade de vida de indivíduos atendidos na atenção primária. Aquichan, v. 16, n. 1, p. 56-66, 2016.

2. JOAQUIM, F. L. et al. Impacto da visita domiciliar na capacidade funcional de pacientes com úlceras venosas. Rev Bras Enferm, v. 69, n. 3, p. 468-477, mai-jun, 2016. 